\title{
Grid-mapping Hellas Planitia, Mars - Insights into distribution, evolution and geomorphology of (Peri)-glacial, fluvial and lacustrine landforms in Mars' deepest basin
}

\author{
M. Voelker*, E. Hauber, F. Schulzeck, R. Jaumann \\ Institut für Planetenforschung, Deutsches Zentrum für Luft- und Raumfahrt (DLR), Rutherfordstraße 2, 12489 Berlin, Germany
}

\section{A R T I C L E I N F O}

\section{Keywords:}

Mars

Hellas planitia

Hydrology

Glaciology

Limnology

Grid-mapping

\begin{abstract}
A B S T R A C T
Traditional maps of Hellas Planitia, the most prominent impact basin on Mars, have focused on the delineation of continuous surface units. We applied the newly developed grid-mapping method in order to quantitatively analyze the distribution and geostatistics of selected (peri)-glacial, fluvial, and lacustrine landforms. The study area was subdivided in grid cells with a mesh size of $20 \times 20 \mathrm{~km}$, and more than 10,000 grids have been inspected manually in a GIS environment at a mapping scale of 1:30,000. Each grid has been checked for the presence or absence of a landform. Thus, we were able to statistically evaluate the geographical behavior of landforms with respect to elevation, slope inclination, aspect, and other parameters. We searched for 24 pre-selected landforms. However, only 15 of them had a sufficient abundance for scientific research. Whereas the latitude-dependent mantle is widespread in most of Hellas, it was found to be mostly missing in the northeastern part, likely a result of desiccating winds circulating clockwise within the basin. The location and morphologic expression of scalloped terrain also seems to be influenced by winds, as the local orientation of scalloped depressions appears to be aligned along the dominant wind direction, indicating that insolation is not the only factor controlling their formation. Hellas Planitia has been suggested as the site of a former sea. We also searched each grid for the presence of possible shorelines. Despite the small scale of our mapping, no clear evidence for coastal landforms has been detected. Our results reveal a distinctive asymmetry with respect to fluvial channels and Noachian lighttoned sediments along the rim of the impact basin. While the northern rim shows a high density of both channels and sediments, the southern counterpart basically lacks channels and light-toned deposits. We suggest different climatic conditions for this imbalance, as the northern part of Hellas likely experienced higher temperatures throughout most of Mars' evolution, while the colder conditions at the southern rim may have prohibited aqueous processes, preventing the development of channels and related sediments. As Hellas contains the deepest areas of the planet's surface, and thus the highest air pressure, its climatic environment can exceed the triple point of water until today, making it a potential habitat. However, our results have shown that the basin floor displays only a very low density of landforms that may indicate liquid water and ice, and especially gullies and viscous-flow features are scarce. The high air pressure and relatively mild temperatures in Hellas decrease the relative atmospheric water content, resulting in a desiccated air and soil, and hence, may explain the lack of viscous-flow features and gullies. All these findings extended our knowledge not only of Hellas Planitia, but of the screened landforms themselves too. In conclusion, small-scale grid-mapping made it possible to recognize large-scale patterns and distributions in Hellas Planitia.
\end{abstract}

\section{Background}

Located in the southern mid-latitudes of Mars, Hellas Planitia is the second-largest confirmed impact basin on the planet, with a diameter of $2300 \mathrm{~km}$. The basin also contains the topographically lowest parts of
Mars, and hence, the highest atmospheric pressure on the planet of up to 14 mbar (Carr, 2006). Air and surface temperatures vary by season from $\sim 150$ to $275 \mathrm{~K}$ and $307 \mathrm{~K}$, respectively (Millour et al., 2015; Forget et al., 1999). Thus, this vast depression is one of the atmospherically most active regions of Mars as shown by the seasonal dust storm activity (e.g.

\footnotetext{
* Corresponding author.

E-mail address: martin.voelker@dlr.de (M. Voelker).
} 
Cantor et al., 2001; Cantor, 2007), and one of the few areas were liquid water might occur on the surface until today (Haberle et al., 2001). These conditions make Hellas a vital region on Mars to understand the distribution of landforms caused by water and ice.

Orbital images show a high diversity of (peri-)glacial, fluvial and possibly lacustrine landforms on the basin floor; some of which are unique to the basin, like the banded terrain (Diot et al., 2014, 2016) or the honeycomb terrain (Bernhardt et al., 2016a). Similar to the northern plains, Hellas also has big outflow channels draining into the basin. This observation led several authors to the assumption that a big lake once existed in Hellas (e.g. Moore and Wilhelms, 2001; Ansan et al., 2011).

Because of its vast size and its high geographical diversity, we have applied the newly developed grid-mapping method (Ramsdale et al., 2017) in an ArcGIS-environment to contextualize the inventory of landforms and the landscape characteristics such as elevation, slope, and aspect. This enabled quantifying the presence of selected landforms with respect to their geographic distribution. Grid mapping has already been applied successfully in the northern Martian lowlands (Brooker et al., 2015; Orgel et al., 2015; Ramsdale et al., 2017; Séjourné et al., 2015; Hauber et al., 2015). In contrast, Hellas Planitia, located on the opposite hemisphere, complements the work of mid-latitudinal and low-elevated landforms on Mars. By applying the grid-mapping method we could examine Hellas for the first time in a high-resolution scale of 1:30,000. Thus, we could examine the evolution of the most recent glacial landforms in Hellas, its hydrological history, and if there are possible ancient shorelines. Moreover, we were able to visualize and investigate the regional distribution patterns in a statistical and cartographic way, thus being able to derive information about the evolution and interaction of several landforms like the latitude-dependent mantle (LDM) and the scalloped terrain.

\subsection{Hellas Planitia}

With a diameter of 1500 to $1900 \mathrm{~km}$ and a depth of up to $8500 \mathrm{~m}$ below the Martian datum, Hellas Planitia is the biggest and deepest obviously visible impact basin on Mars (Fig. 1 and Fig. 2). Formed $3.99 \pm 0.01 \mathrm{Ga}$ ago (Werner, 2008) by an impactor measuring approximately $550 \mathrm{~km}$ (Arkani-Hamed, 2005), it is the most distinct physiogeographic feature on the southern highlands. Its highly elliptical form either suggests that Hellas Planitia might be a double-impact basin (Arkani-Hamed, 2010) or an oblique impact event (Leonard and Tanaka, 2001). Despite of its size, no inner impact rings can be distinguished. The rim of the basin is severely dissected. Only its northwestern half is more or less intact. To the east, the rim is breached by the so-called Hella$\mathrm{s}$-Hesperia trough (HHT), and to the south by Malea Planum. Especially the latter is important for the climatic conditions of the Hellas basin as it induces the influx of cold air draining down from south polar highlands.

The landforms within Hellas are very diverse. Its discontinuous rim rises up to $5000 \mathrm{~m}$ above the interior plains. Two breaches in the rim, measuring between 600 and $900 \mathrm{~km}$, occur in the east and southwest. Both gaps are apparently caused by volcanic processes, and show significant outflow channels, e.g. Dao Vallis, Harmakhis Vallis and Axius Valles (Tanaka and Leonard, 1995; Leonard and Tanaka, 2001; Williams et al., 2010). The bottom of Hellas Planitia can be separated into three

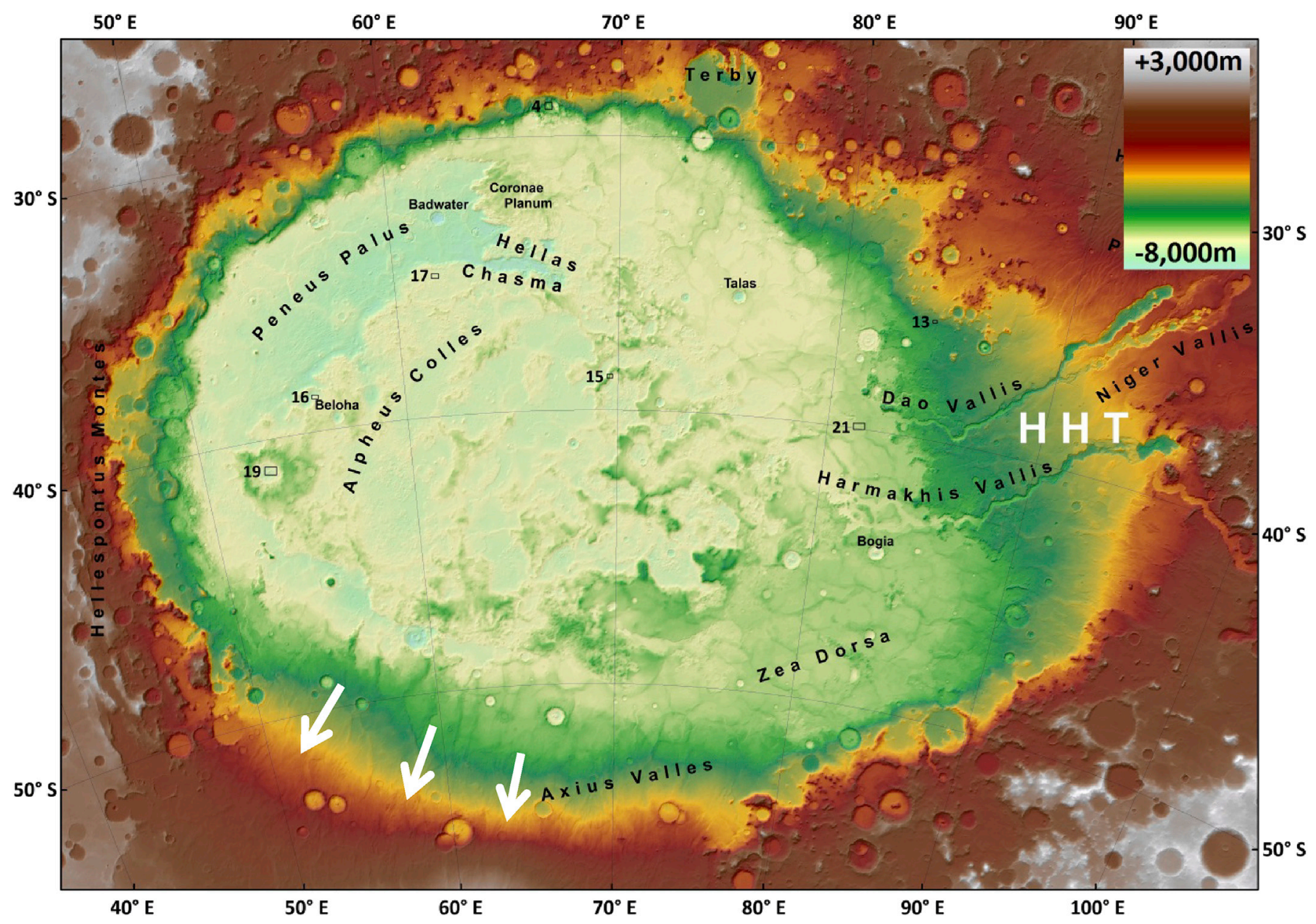

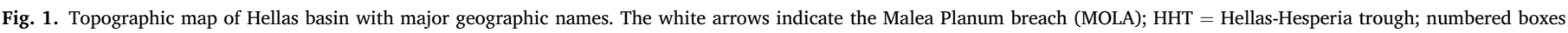
indicate locations of the corresponding figures. 


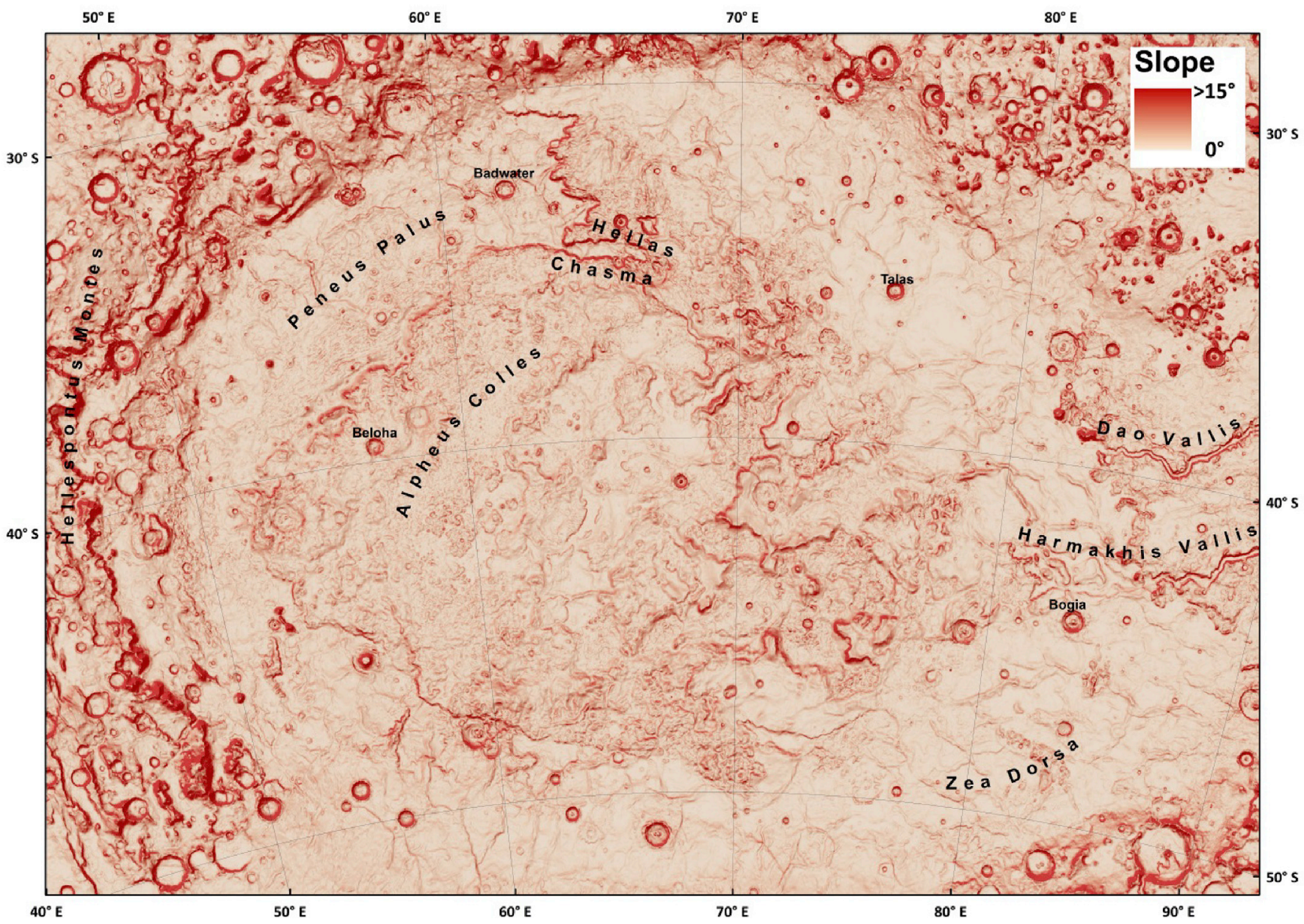

Fig. 2. Slope map based on MOLA data. Stereographic projections centered at $\lambda=69^{\circ}, \varphi=-49^{\circ}$.

major regions; Peneus Palus in the northwest is the lowest plain in Hellas and is mainly a flat and level lowland. However, it also contains some landforms, i.e. the honeycomb and reticulate terrain (Diot et al., 2014), that seem to be unique in Hellas. Moreover, there are several solitary peaks, located in circular depressions (Zuschneid and van Gasselt, 2014). At its easternmost point, Hellas Chasma, an up to 1000 m-deep trough measuring $160 \mathrm{~km}$ in length and around $22 \mathrm{~km}$ in width. The second major region is characterized by the hilly terrain of Alpheus Colles, which covers the central plains of Hellas and shows a rugged surface consisting of myriads of rounded knobs. The most enigmatic landform is the so-called banded terrain (Diot et al., 2014, 2016), which seems to be linked to the adjacent honeycomb and reticulate terrain in Peneus Palus. The third major region is an unnamed plain in eastern Hellas. It consists of an extensive set of wrinkle ridges, and is cut by Dao and Harmakhis Valles, which are crossing through this plain. Several chaotic terrains are located at the border between this area and Alpheus Colles. At its northwestern end this region transitions into Coronae Planum, a relatively small plain with a very smooth surface.

The geology of Hellas Planitia has already been mapped by several authors (e.g. Leonard and Tanaka, 2001; Bernhardt et al., 2016a). Both suggest intensive Noachian and Hesperian magmatic activity and fluvial erosion on the basin's floor and rim, linked to the adjacent volcanic provinces to the east and south. Since the late Hesperian, intensive aeolian erosion affected the research area. Geophysically, the Martian crust shows in Hellas Planitia its lowest thickness values of just $5-15 \mathrm{~km}$ (Neumann et al., 2004).

Climatically, Hellas Planita is of global importance. Its high air pressure is unique on the planet. Together with surface temperature highs of up to $307 \mathrm{~K}$ (Millour et al., 2015; Forget et al., 1999), its environment can exceed the triple point of water easily. Moreover, it is one of the major topographical depressions on the planet having a high air pressure, and hence, being able to lift dust particles and produce dust storms (Cantor et al., 2001; Cantor, 2007). They are mainly caused by strong wind currents within the basin, which, in turn, are a result of Hellas Plantia's location and morphological arrangement (e.g. Ogohara and Satomura, 2008). Wind currents rotate clockwise in Hellas (Ogohara and Satomura, 2008; Howard et al., 2012), caused by two factors; (1) the breached rim at Malea Planum in SW Hellas supports katabatic winds, draining down northwards from cold south polar highlands (Howard et al., 2012), and (2) global westerlies in southern mid-latitudes force the air in northern Hellas to move east (Kahre et al., 2014). Several authors suggest these strict wind directions are the reason for the today's morphology of the basin floor. For example, Howard et al. (2012) and Bernhardt et al. (2016a) hypothesize the evolution of the Peneus Palus depression might be caused by aeolian erosion. Another climatic phenomenon is the extension of the south polar cap up to $50^{\circ} \mathrm{S}$, affecting the southernmost part of Hellas (Hansen et al., 2010).

\section{Data \& methods}

A Digital Elevation Model (DEM) derived from MOLA data (Smith et al., 1999, 2001) was used to prepare a base map for definition of the study area and the design of the grid mapping. The margins of the examined area are based on topography (mountain ranges along the rim) and an elevation of $5500 \mathrm{~m}$ below the Martian datum (where no obvious rim is visible). The total area examined is about $8,000,000 \mathrm{~km}^{2}$. The basic 
grid map has been generated automatically in a polygonal shapefile using the Repeating Shapes tool in ArcGIS 10.3 (Jenness, 2012). Thus, Hellas Planitia was separated into approximately 20,000 grids, each with a dimension of $20 \times 20 \mathrm{~km}$. For minimizing geometric distortion of geomorphological features we used a stereographic projection centered at $\lambda=69^{\circ}, \varphi=-49^{\circ}$.

The actual grid-mapping work has been carried out by photogeological interpretations. To balance between completeness and effective mapping, we only examined every second grid. The missing grids were later interpolated automatically (see below). The attribute table of the shapefile has been extended into several columns for the collected information. See Table 1 for the gathered parameters. Each parameter has been categorized into one of the classes mentioned in Table 2. Besides the landforms, we also gathered information about CTX quality and coverage of the grid. More than $93 \%$ of all grids have a complete CTX coverage, and $99 \%$ are covered by more than two thirds, whereas $96 \%$ of all CTX covered grids have a medium to good quality.

We decided to produce a $20 \times 20 \mathrm{~km}$ raster in order to (1) compare our results to the work done by Orgel et al., 2015; Ramsdale et al., 2017; Séjourné et al., 2015; Hauber et al., 2015 in Vastitas Borealis, as these studies used the same grid size, and (2) as this mesh size is adequate for such an extensive study area. To ensure that our work is consistent and uniform only one mapper, the main author of this text, has executed the grid mapping in Hellas.

Every grid has been mapped at a scale of $1: 30,000$ on the basis of CTX images (Context Camera onboard Mars Reconnaissance Orbiter; Malin et al., 2007). CTX images are the main data basis for producing a reliable map as they provide both a sufficient resolution (ground pixel size $\sim 6 \mathrm{~m}$ ) and spatial coverage. Other datasets used in this study are MOLA (Smith et al., 1999, 2001), THEMIS nighttime imagery (Christensen et al., 2004; Fergason et al., 2006; see Fig. 3), and the dust cover index (DCI; Ruff and Christensen, 2002), see Fig. 4. We extracted from the MOLA dataset elevation, slope inclination (Fig. 2), and aspect for each grid as well as the average TI and DCI values by using the "Zonal Statistics" tool in ArcGIS.

After data collection the missing grids were interpolated by simple spreadsheet calculations. To ensure a reliable interpolation of an unmapped grid a weighting factor was used, including 12 surrounding mapped grids into the calculation (Fig. 5). "No data" values [4] have been excluded. Along the margins of the research area the weighting factor needed to be adjusted for preventing distortions caused by the unmapped grids of the rectangular shapefile outside of the circular study area.

The raster values of four external parameters (elevation, slope inclination, thermal inertia (TI), and dust cover index (DCI)) were averaged (mean) for each grid based on MOLA, THEMIS-nighttime or DCI datasets. It is important to mention that the values for slope inclination do not consider local slopes as their values average all slopes within one $20 \times 20 \mathrm{~km}$ grid; this concerns especially the interpretation of small-scale landforms such as gullies. Thus, we are only able to analyze their distribution regionally. For aspect (azimuth) we used the majority function in ArcGIS 10.1. THEMIS nighttime mosaics were used for relative comparisons of thermophysical surface properties, as the enormous

Table 1

Gathered features and parameters for the study area.

\begin{tabular}{ll}
\hline Ice-related landforms & Water-related landforms \\
\hline Banded terrain & Channels \\
Gelifluction & Chaotic terrain \\
Large-pitted mounds & Fans \\
Latitude-dependent mantle (LDM) & Gullies \\
Layered-remnant deposits (LRD) & Light-toned deposits (LTD) \\
Lineated terrain (LT) & Sheet deposits \\
Polygons & Shorelines \\
Reticulate terrain & Viscous-flow features (VFF) \\
Scalloped terrain & \\
Other landforms & Imagery \\
Dunes & CTX coverage \\
Honeycomb terrain & CTX quality \\
\hline
\end{tabular}

Table 2

Categories used in grid-mapping.

\begin{tabular}{lll}
\hline Categories & \\
\hline 0 & absent & landform not observed \\
1 & possible & landform cannot be certainly determined \\
2 & present & landform occurs but does not prevail \\
3 & dominant & landform covers most of the grid \\
4 & no data/not compiled & grid has no CTX coverage \\
\hline
\end{tabular}

dimensions of Hellas made it unpractical to process single THEMISnighttime swaths.

Statistic evaluations, diagrams, and graphs were carried out in a Python and spreadsheet environment. For these calculations only the values "present" and "dominant" were considered as they ensure the presence of a landform; so "possible" values were strictly excluded and are only visible in maps. In order to compare the spatial distribution of the landforms regarding their elevation, slope angle, aspect, TI, and DCI we created box-whisker plots Python. These plots also provide information about median, quartiles, interquartile range, and dispersion of each landform. It needs to be emphasized that these graphs can only show trends as the landforms are not distributed normally, e.g. regarding their elevation. However, it is possible to extract information in which conditions and environments each landform predominantly occurs.

We subdivided each of the five parameters into several classes (Table 3). According to the formula developed by Sturges (1926) we needed to develop at least 16 classes/bins (based on a sampling size of 20,099 grids) for each parameter. But in order to receive a higher data resolution we extended the amount of classes for each parameter by establishing even figures (e. g. each bin in elevation is $200 \mathrm{~m}$ wide instead $475 \mathrm{~m}$ when applying 16 classes). For each of these normalized diagrams we merely included bins containing more than 30 samples, in order to guarantee statistical reliability (Bahrenberg et al., 1999). For TI and DCI only spatially extensive landforms have been considered (banded terrain, honeycomb terrain, LDM, scalloped terrain, sheet deposits, and light-toned deposits) as small or linear landforms, for instance gullies, are not sufficiently significant within a $20 \times 20 \mathrm{~km}$ grid. For understanding the behavior of one landform, e.g. regarding a potential elevation-dependent distribution, we created normalized line graphs in order to remove the sampling bias (absolute graphs are strongly dependent on the research area's topography, and thus, biased). Normalized values are based upon elevation, slope, aspect, DCI, or THEMIS (Table 3), giving the density of a landform by class; e.g. the density of channels at an elevation of $-3000 \mathrm{~m}$ is 0.3 , and hence, $30 \%$ (see Fig. 20). This statistical correction is necessary for classes that are underrepresented in Hellas, e.g. grids with an elevation higher than -4400 always contain less than 200 grids (Table 3 ).

As the results of THEMIS only provide relative grey scale values, and hence a low information content, we shifted the plot to the supplements of this paper. However, the thermal inertia results of most of the landforms are presented in textual form in chapter 3.

We also considered if the mapping could be performed automatically, e.g. by supervised classifications. However, most of the landforms are either linear and therefore not suited for 2D classifications (e. g. dark pixelated channels might be confused with dark pixelated crests or dust devil tracks), diffuse (e. g. lineated terrain often has not clear margin), or request the interpretive skills of a human researcher (e.g. possible shorelines, alluvial fans).

\section{Landforms and results}

In this section we provide for each of the mapped landforms a short characterization together with the related mapping results. The landforms were separated into three classes: ice-related landforms, waterrelated landforms, and others. Figs. 7, 9, and 11 represent the results of the absolute distribution of landforms by classes, and Figs. 8, 10, and 12 


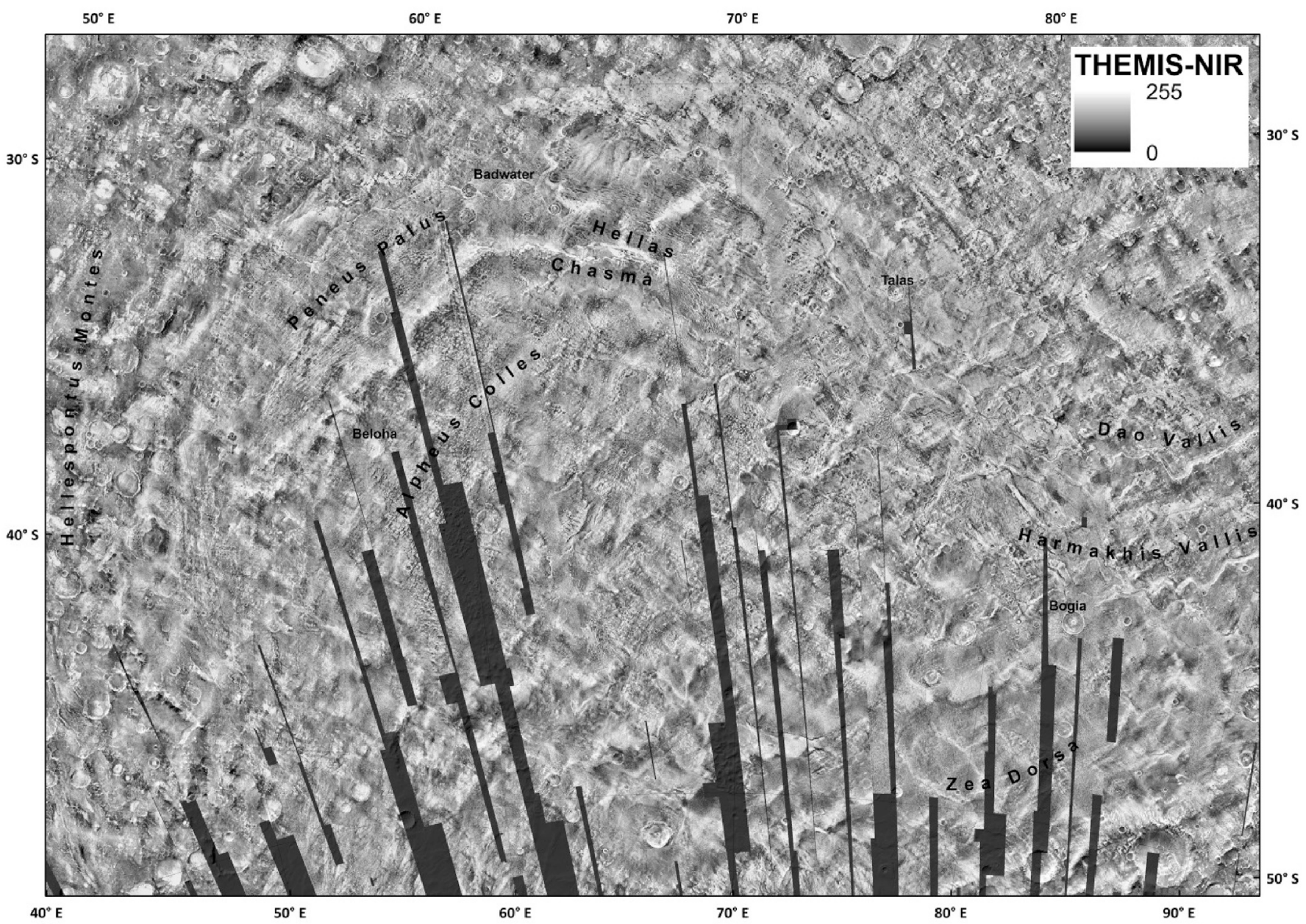

Fig. 3. THEMIS-nighttime imagery (8-bit) for Hellas (USGS). Stereographic projections centered at $\lambda=69^{\circ}, \varphi=-49^{\circ}$

the relative occurrences. Fig. 23 provides an overview of the suggested stratigraphy of the mapped landforms.

\subsection{Topography}

For the research area in Hellas Planitia we calculated a differential hypsometric curve (Fig. 6), which shows that $76 \%$ of the $20 \times 20 \mathrm{~km}$ grids are at an elevation range between -6000 and $-7500 \mathrm{~m}$ below the Martian datum line. Its low-point, which is also the lowest point on the Martian surface, is located in Badwater crater $\left(33^{\circ} \mathrm{S}, 62^{\circ} \mathrm{E}\right)$ at an elevation of $-8194 \mathrm{~m}$. The highest elevation of $-12 \mathrm{~m}$ is an unnamed peak in the Hellespontus Montes on top of the western rim of Hellas Planitia. Despite the significant absolute relief, slope inclination is relatively low. $48 \%$ of all grids have an inclination of $1^{\circ}, 21 \%$ show $2^{\circ}$, and further $20 \%$ show an inclination of $3^{\circ}$ or higher.

\subsection{Ice-related landforms}

Due to its location in the southern mid-latitudes, Hellas Planitia is strongly affected by the latitude-dependent mantle (LDM), which is thought to be a mixture of ice and dust (Mustard et al., 2001; Kreslavsky and Head, 2002; Schon et al., 2009, 2012; Kostama et al., 2006) and contains a significant amount of ice (46-94\% by volume; Conway and Balme, 2014) below a desiccated surface lag (Fig. 14 and Fig. 15). The thickness of this lag ranges between $0.25 \mathrm{~m}$ and $8 \mathrm{~m}$, with a mean thickness of $3.2 \mathrm{~m}$ (Conway and Balme, 2014). This lag decreases in thickness with decreasing distance to the poles (Feldman et al., 2004; Mangold, 2011). The LDM appears to be a layered deposit. The evolution of each layer likely depends on factors like orbital excursions of the planet's axial tilt, precession, and eccentricity (e.g. Kreslavsky and Head, 2002; Head et al., 2003; Kostama et al., 2006; Dickson et al., 2015). Especially during high obliquity periods surface ice remains stable at the mid-latitudes (e.g. Levrard et al., 2004; Mischna et al., 2003; Forget and Haberle, 2006). Moreover, the atmosphere contains more dust during these phases. The dust particles act as condensation nuclei for the ice (Richardson and Wilson, 2002; Haberle et al., 2003), and as soon as these ice/dust particles grow big enough, they start to fall by gravitation and deposit. It is unclear if this process is still active on Mars or if it is just temporarily halted because of an ongoing interglacial period (Head et al., 2003; Madeleine et al., 2014). However, according to crater-size frequency distributions, the latest LDM was deposited in geologically recent times (0.1-2.1 Ma) (Kostama et al., 2006; Willmes et al., 2012). At certain environmental conditions, such as during high obliquity phases, high temperatures, and/or aeolian activities, LDM appears to be susceptible to sublimation (e.g. Mangold, 2011; Dundas et al., 2015a) and/or melting processes, causing degradation or deformation, into several characteristic morphologies, e.g. scalloped terrain (Morgenstern et al., 2007; Lefort et al., 2009; Ulrich et al., 2010; Zanetti et al., 2010; Willmes et al., 2012; Dundas et al., 2015a), the so-called lineated terrain, and possibly layered remnant deposits (LRD) (Morgenstern et al., 2007) within small craters. Another potential sublimation feature found in Hellas is the dissected terrain; a thin blanket of LDM perforated by small and erratically shaped sublimation pits. Its thickness varies between a few meters to tens of meters (Mangold, 2011). Mangold (2011) suggests that these sublimation pits are the result of ongoing active sublimation on Mars. 

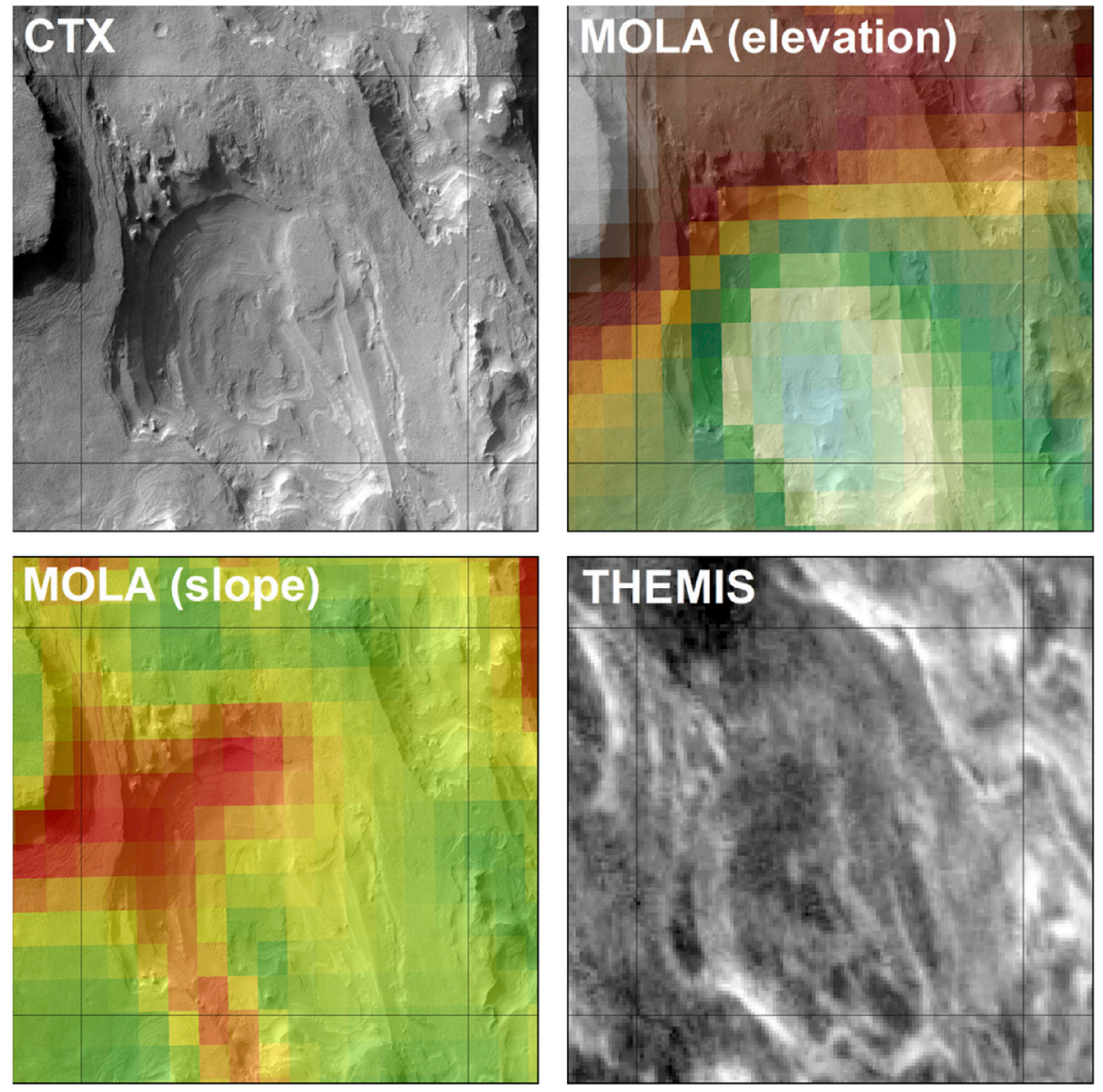

Fig. 4. Multilayer coverage of an exemplary grid cell; $20 \times 20 \mathrm{~km}$, north is up (image is centered at $28.8^{\circ} \mathrm{S}, 67.0^{\circ} \mathrm{E}$ ).

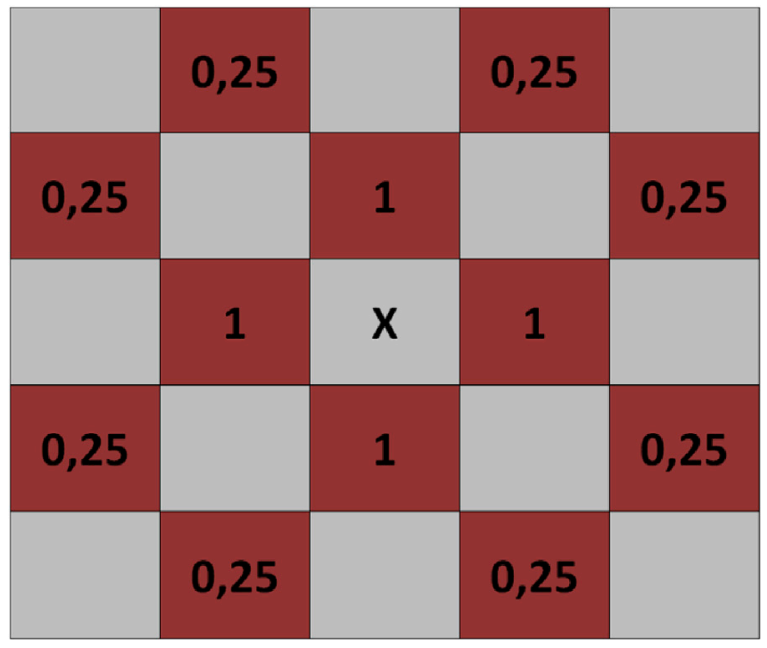

Fig. 5. Weighting factors used for the interpolation of the grids. The dark grids represent values that have been mapped manually. The bright grids were originally empty. For interpolating the missing grids we multiplied and averaged the mapped grid, using the weighting factors as shown above.

Because of its enormous size, depth, and hence, high air pressure, Hellas is a significant sedimentary trap for this atmospherically-derived deposit (Fig. 14). Approximately $90 \%$ of the study area is draped by this mantling deposit, except for a region in northeastern Hellas, which extends from Talas crater $\left(35.5^{\circ} \mathrm{S}, 75.5^{\circ} \mathrm{E}\right)$ to the lower termination of Harmakhis Vallis (Fig. 14). This NW to SE trending elliptical gap in LDM coverage extends over an area of $200 \times 800 \mathrm{~km}$. This observation is consistent with the roughness map of Kreslavsky and Head (2002), because this area shows high roughness values, which independently indicates that the local small-scale relief is not muted or smoothed by the deposition of LDM. The gap also correlates to an area with less water-equivalent hydrogen $(<3 \%)$ as compared to the rest of Hellas Planitia with 4-6\% (Feldman et al., 2004). Immediately east of this gap is an area being covered by a thin coat of LDM (dissected terrain). Beneath this blanket there is clear evidence of underlying but muted volcanic and/or fluvial morphologies (Fig. 13), suggesting that this region has only been covered by a thin LDM sheet, possibly deposited during one of the last obliquity excursions. Other, but much smaller LDM-free regions are located along Hellas' northern $\operatorname{rim}\left(<30^{\circ} \mathrm{S}\right)$, as well as another elongated spot $(70 \times 100 \mathrm{~km})$ in northern Peneus Palus. The rest of the basin is covered with LDM. However, there are areas showing a rougher texture of LDM than other parts. For example, LDM in the central and southern part of Hellas displays a relatively smooth texture, and appears to be young. In contrast, around this central area, in the southwestern, southeastern and northern part of the basin floor, the mantling deposit is often severely degraded. Especially north of $35^{\circ} \mathrm{S}$ LDM is characterized by a rough texture. THEMIS nighttime datasets show a slight trend of LDM covered grids to lower TI values.

Scalloped terrain is referred to line symmetric and rimless depressions within LDM (e.g. Morgenstern et al., 2007), measuring a few tens to several hundred meters in diameter (Fig. 15). Their depth ranges from a few meters to tens of meters. On the southern hemisphere they show a relatively steep $\left(15^{\circ}-30^{\circ}\right)$ pole-facing scarp and a smooth and gently inclined $\left(2^{\circ}\right)$ equator-facing slope. The steep scarp is stationary, while the smooth slope retreats progressively (Mangold, 2011; Séjourné et al., 2011). They occur isolated or in clusters. Scalloped terrain is especially 
Table 3

Classification for each parameter for linear graphs. Parameter bins with a sample size (population) of less than 30 have been neglected in order to exclude a sampling bias.

\begin{tabular}{|c|c|c|c|c|c|c|c|c|c|}
\hline \multicolumn{6}{|l|}{ MOLA } & \multicolumn{2}{|l|}{ THEMIS } & \multicolumn{2}{|l|}{ TES } \\
\hline Elevation & Total & Aspect & Total & Slope & Total & Thermal Inertia & Total & DCI & Total \\
\hline \multicolumn{2}{|l|}{$[\mathrm{m}]$} & \multicolumn{2}{|l|}{$\left[{ }^{\circ}\right]$} & \multicolumn{2}{|l|}{$\left[{ }^{\circ}\right]$} & \multicolumn{2}{|l|}{ [grey values] } & \multicolumn{2}{|l|}{ [emissivity $\varepsilon$ ] } \\
\hline$\leq-7800$ & 17 & 0 & 1878 & 0.00 & 39 & 0 & 572 & $\leq 0.941$ & 59 \\
\hline-7600 & 98 & 25 & 1967 & 0.25 & 1279 & 10 & 97 & 0.942 & 53 \\
\hline-7400 & 326 & 50 & 1301 & 0.50 & 2564 & 20 & 85 & 0.943 & 63 \\
\hline-7200 & 470 & 75 & 914 & 0.75 & 3002 & 30 & 105 & 0.944 & 130 \\
\hline-7000 & 1239 & 100 & 969 & 1.00 & 2715 & 40 & 122 & 0.945 & 211 \\
\hline-6800 & 2476 & 125 & 1411 & 1.25 & 2313 & 50 & 105 & 0.946 & 352 \\
\hline-6600 & 3251 & 150 & 1832 & 1.50 & 1683 & 60 & 123 & 0.947 & 458 \\
\hline-6400 & 2881 & 175 & 2241 & 1.75 & 1344 & 70 & 172 & 0.948 & 619 \\
\hline-6200 & 2374 & 200 & 1779 & 2.00 & 991 & 80 & 303 & 0.949 & 761 \\
\hline-6000 & 1764 & 225 & 1227 & 2.25 & 787 & 90 & 676 & 0.950 & 912 \\
\hline-5800 & 992 & 250 & 717 & 2.50 & 513 & 100 & 1607 & 0.951 & 1148 \\
\hline-5600 & 700 & 275 & 612 & 2.75 & 432 & 110 & 3097 & 0.952 & 1157 \\
\hline-5400 & 600 & 300 & 696 & 3.00 & 398 & 120 & 4265 & 0.953 & 1267 \\
\hline-5200 & 458 & 325 & 1197 & 3.25 & 331 & 130 & 3927 & 0.954 & 1378 \\
\hline-5000 & 349 & 350 & 1358 & 3.50 & 244 & 140 & 2480 & 0.955 & 1308 \\
\hline-4800 & 274 & & & 3.75 & 200 & 150 & 1364 & 0.956 & 1319 \\
\hline-4600 & 253 & & & 4.00 & 162 & 160 & 590 & 0.957 & 1195 \\
\hline-4400 & 250 & & & 4.25 & 150 & 170 & 205 & 0.958 & 1059 \\
\hline-4200 & 164 & & & 4.50 & 101 & 180 & 69 & 0.959 & 988 \\
\hline-4000 & 167 & & & 4.75 & 111 & $\geq 190$ & 26 & 0.960 & 883 \\
\hline-3800 & 183 & & & 5.00 & 90 & & & 0.961 & 772 \\
\hline-3600 & 141 & & & 5.25 & 83 & & & 0.962 & 621 \\
\hline-3400 & 118 & & & 5.50 & 66 & & & 0.963 & 614 \\
\hline-3200 & 92 & & & 5.75 & 53 & & & 0.964 & 505 \\
\hline-3000 & 53 & & & 6.00 & 58 & & & 0.965 & 477 \\
\hline-2800 & 66 & & & 6.25 & 27 & & & 0.966 & 365 \\
\hline-2600 & 51 & & & 6.50 & 28 & & & 0.967 & 320 \\
\hline-2400 & 39 & & & 6.75 & 32 & & & 0.968 & 229 \\
\hline-2200 & 53 & & & $\geq 7.00$ & 194 & & & 0.969 & 210 \\
\hline-2000 & 31 & & & & & & & 0.970 & 169 \\
\hline \multirow[t]{5}{*}{$\geq-1800$} & 60 & & & & & & & 0.971 & 108 \\
\hline & & & & & & & & 0.972 & 95 \\
\hline & & & & & & & & 0.973 & 54 \\
\hline & & & & & & & & 0.974 & 44 \\
\hline & & & & & & & & $\geq 0.975$ & 85 \\
\hline
\end{tabular}

common in Utopia Planitia and Malea Planum (Zanetti et al., 2010; Lefort et al., 2009). The two prevailing scenarios for the volume loss is either sublimation of the LDM material (e.g. Lefort et al., 2009; Zanetti et al., 2010; Dundas et al., 2015a) or melting (Soare et al., 2007, 2008, 2011) of subsurficial ice, and hence, the collapse of the overlying material.

The scalloped terrain in Hellas Planitia occurs in scattered locations mostly south of $35^{\circ} \mathrm{S}$ (Fig. 14). It displays two shapes: the typical isolated or merged ovoid form as well as a widespread, irregular and ripple-like shape. Pits of the latter type are much smaller than the classic scalloped pits (Fig. 15). Both can occur next to each other. Extended populations are found in southwest Hellas close to the breached rim where the basin transitions into Malea Planum. This geomorphology is generally found on medium to high elevations and rarely in low elevations. It preferentially occurs on steeper slopes (Fig. 10). Its aspect maximum is towards north and the minimum towards south. TI values show no obvious correlation with scalloped terrain. The DCI values of scalloped terrain show a trend towards low dusty areas (Fig. 12).

The term banded terrain describes a smooth and two-dimensionally convoluted layered unit covering the landscape, caused by viscous flow of either ice-rich volcanic debris or an ice-dust mixture (Diot et al., 2016) (Fig. 16). Although not fully understood yet, the process that formed the banded terrain in the Amazonian (Diot et al., 2014) is one of the most recent surface processes in Peneus Palus, and probably affected larger parts of this lowland.

The banded terrain mainly occurs on top of the westernmost part of the Alpheus Colles plateau (Fig. 14). There are also minor occurrences along the inner western and southwestern rim of Hellas and within an isolated mountain range in the Zea Dorsa region. The relative frequency of the banded terrain is decreasing slightly from -7500 to $-4500 \mathrm{~m}$.
Slope inclination tends to values between $2^{\circ}$ and $4^{\circ}$ and its maximum aspect values are towards $\mathrm{E}$ and NW. The banded terrain has a slight trend to higher TI values, and a significant trend towards strongly dust covered areas (Fig. 12). Moreover, there is no evidence that the banded terrain is susceptible to the formation of scalloped terrain.

Layered remnant deposits (LRD) were first described as layered material by Morgenstern et al. (2007) in Utopia Planitia. They suggested these subhorizontal deposits within craters are remnants of an older LDM that survived the removal of LDM in protected areas. This is why we extended the term into layered remnant deposits (LRD) (Fig. 17).

LRD are predominantly found at elevations higher than $-5000 \mathrm{~m}$, and slightly tend to occur on slopes with an inclination of $2^{\circ}$ and $5^{\circ}$ in the normalized graphs (Fig. 10). At HiRISE resolution LRD seem to be a brittle and sometimes polygonally fractured material. They predominantly occur in small to medium-sized craters of less than $2 \mathrm{~km}$ in diameter, except in NE Hellas were they only occur in craters larger than $3 \mathrm{~km}$. Interestingly, there are places where some craters contain LRD, but adjacent craters of the same size do not, despite appearing neither younger nor older. The grids containing LRD have a maximum aspect towards $\mathrm{S}$ and a minimum towards $\mathrm{N}$. As they mainly occur in the northern latitudes of Hellas Planitia $\left(<38^{\circ} S\right)$, however, their large-scale aspect is strongly biased by the pole-facing interior slopes dominating the northern part of Hellas. Their preferred local aspect within each crater displays an opposite trend. LRD mostly occur on the inner northfacing wall of medium-sized craters, and in the center of small craters. A weak trend towards areas with low dust cover is visible in the DCI.

Viscous-flow features (VFF) are thought to be the result of creep processes of icy material (e.g. Milliken et al., 2003; Van Gasselt et al., 2007a). Here we classify all icy mass wasting deposits as VFF (glacier-like 


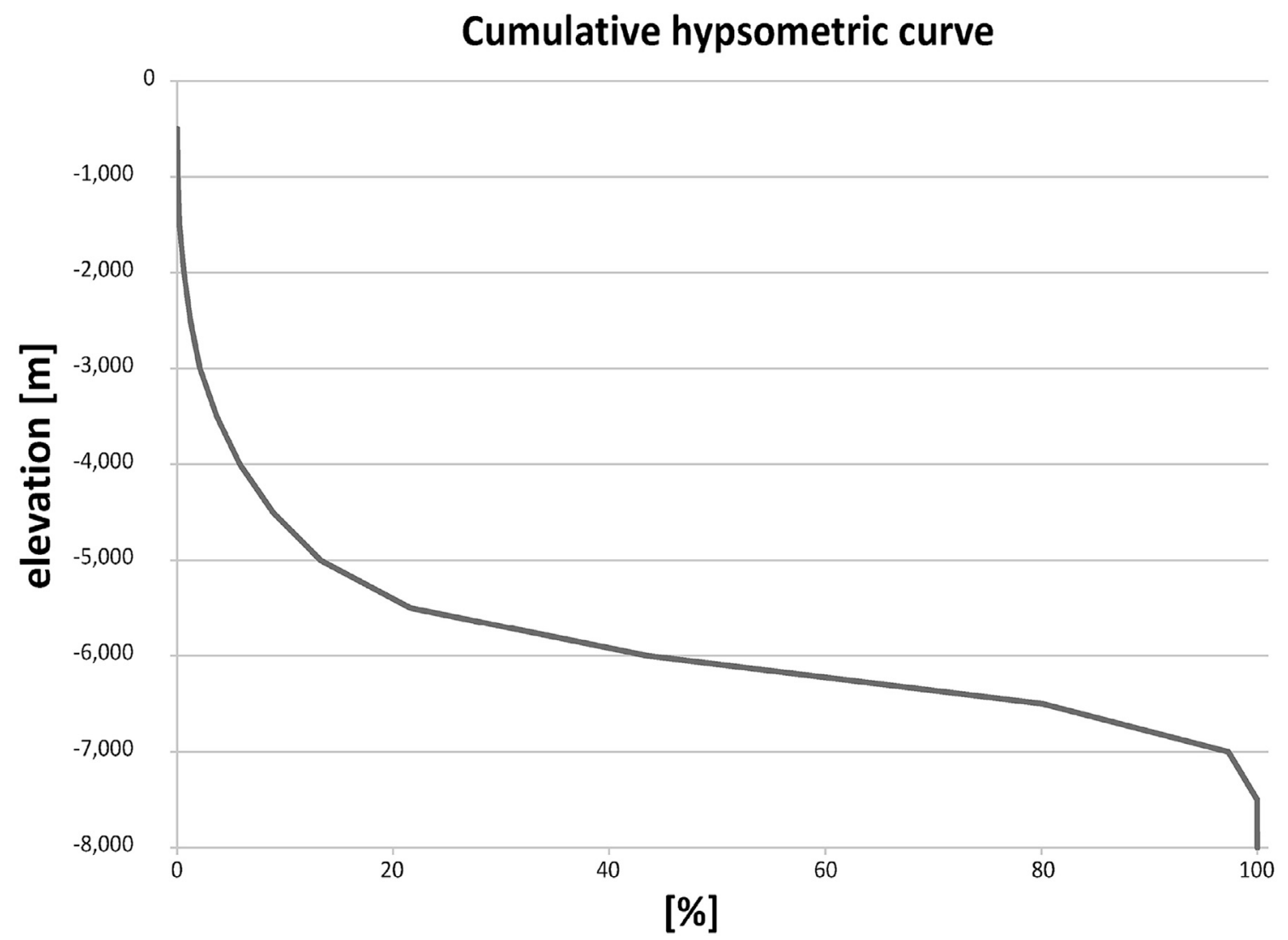

Fig. 6. Hypsometric curve for Hellas based on MOLA and the $20 \times 20 \mathrm{~km}$ grid.

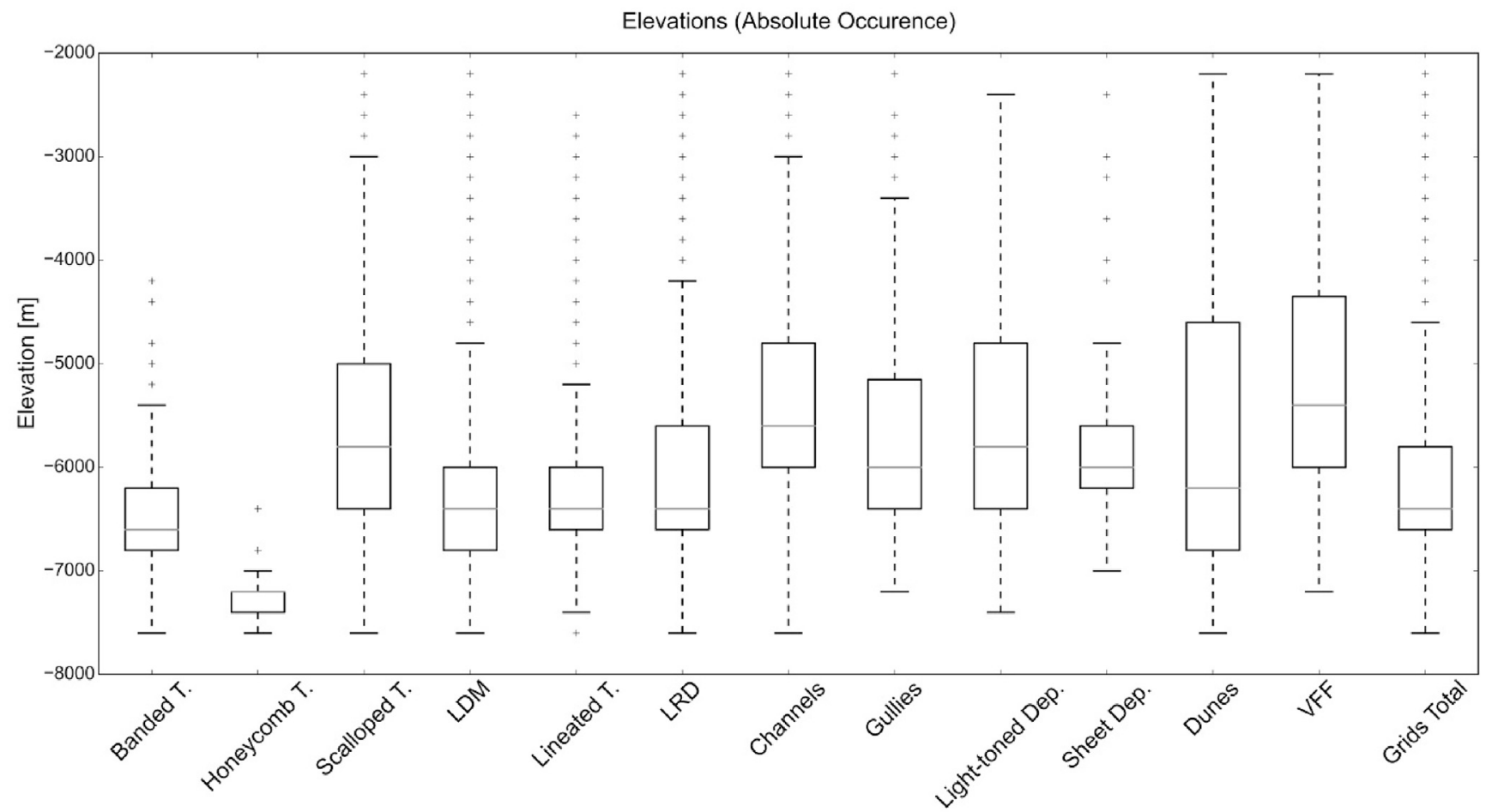

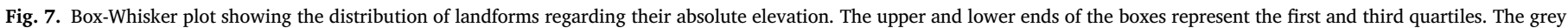
line within the box is the median (second quartile). The whiskers/antennas display the $\times 1.5$ IQR (interquartile range). The plus marks show extreme values.

flows, lineated valley fills, lobate debris aprons). Milliken et al. (2003) proposed that VFF's were formed in a $10 \mathrm{~m}$-thick layer with high amounts of ice, which is currently being degraded. The global distribution of VFF is apparently linked to the distribution of LDM (Milliken et al., 2003; Van 
Gasselt et al., 2010). The mapped VFF also include glacier-like features (Hubbard et al., 2014).

VFF mainly occur on elevations higher than $-5000 \mathrm{~m}$; below this datum there are almost no VVF (Fig. 8) despite the presence of a significant relief at the basin floor (see Fig. 2). VFF are mostly observed on slopes steeper than $3^{\circ}$ (Fig. 10), with a preferred aspect peak towards $\mathrm{E}$ and a further but smaller peak towards W (Fig. 22). This aspect distribution is similar to that of the banded terrain. VFF tend to have higher TI values and low dust coverage (Fig. 12).

The informally named lineated terrain appears to be a degraded or deformed variation of LDM (Fig. 15). Its surface is rough, undulated, and furrowed. The furrows are arranged parallel to the slopes. Within Hellas Planitia, the LDM has two different forms: an older and deformed variety (here referred to as lineated terrain) is underlying a younger and smooth variety (here referred to as LDM). Lineated terrain is often exposed within smooth LDM, similar to nunataks (especially in Alpheus Colles region).

In Hellas, the lineated terrain is probably an older and degraded LDM deposit with a rough surface, and is widely superposed by the youngest LDM deposit. It mainly occurs at elevations between -6500 and $-4500 \mathrm{~m}$ (Fig. 8). Its slope inclination maximum ranges from $2^{\circ}$ to $4^{\circ}$ (Fig. 10), and its aspect maximum is from E over N to W. Geographically, the lineated terrain concentrates in central Hellas, with smaller accumulations along the western and southwestern rim. In the Alpheus Colles region it is partially arranged in arcuate bands up to $300 \mathrm{~km}$ in length, and seems to be linked to the large pitted mounds (see paragraph for large-pitted mounds below). On the other hand, the lineated terrain and large pitted mounds apparently exclude each other; hence they both only occur adjacent to each other, but rarely together. Areas with a high density of lineated terrain are Coronae Planum, Alpheus Collesa, a rugged plain between Hellas Chasma and Talas crater, and the mountains at the terminations of Dao and Harmakhis Valles. In these areas this terrain type is severely lineated and possibly deformed. In THEMIS-NIR data it has no preference for higher or lower TI values. However, the DCI shows a strong trend towards significant dust coverage (Fig. 12).

\subsection{Water-related landforms}

Two types of channels are present in the study area: large outflow channels (Figs. 1 and 21) and small (in some cases dendritic) channel networks. Several huge outflow channels drain into Hellas, i.e. Dao, Niger, Harmakhis, and Reull Valles. All of them are considered to be of late Hesperian to early Amazonian age, and they were probably formed by volcanic and/or tectonic processes (e.g. Leonard and Tanaka, 2001; Mest and Crown, 2001; Kostama et al., 2010). All of them are located at Hellas' eastern rim. The smaller channel networks (Navua Valles, Sungari Vallis, Mad Vallis, Axius Valles) show shallow and narrow valleys up to several hundreds of kilometers in length. They are also partially branched, and show no obvious source. Therefore, they may have either formed by surface runoff and/or ground-water sapping (Crown et al., 2005). Zuschneid and van Gasselt (2007) analyzed the age of the area around Sungari Vallis and found that the fluvial resurfacing events took place during the mid-to late Amazonian ( $\sim 350-750 \mathrm{Ma})$.

Channels are visible almost everywhere along the whole rim (Fig. 18). On the southern rim the density of channels is slightly lower. The highest densities occur along the eastern rim where the big outflow channels drain into Hellas Planitia. On the floor of the basin the spatial density of this type of landform is very low. Channels mainly appear at higher elevations (Figs. 8 and 20) and steeper slopes. Their slope distribution mainly ranges from $3^{\circ}$ to $5^{\circ}$ (Fig. 10). Grids with channels generally have higher TI and DCI values, corresponding to a low dust coverage (Fig. 12).

Light-toned deposits (LTD) were already studied intensely in the Hellas region (Fig. 19 and Fig. 20) especially along its northern and western rim and the high plains surrounding the impact basin (e.g. Wilson et al., 2007; Ansan et al., 2011; Carter et al., 2013; Bandfield et al., 2015; Chuang et al., 2015; Salese et al., 2016). The most prominent aqueous minerals in northern Hellas are $\mathrm{Fe} / \mathrm{Mg}$ smectites of Noachian origin (Ansan et al., 2011). Moreover, chlorites, and opaline silica have been detected (Carter et al., 2013). Ansan et al. (2011) examined an extensive and thick sedimentary body in Terby crater, located on the northern rim of Hellas. They found evidences that the phyllosilicate-bearing LTD might be remnants of an ancient Noachian-aged fluvial deposit, which was eroded

Elevations (Relative Occurence)

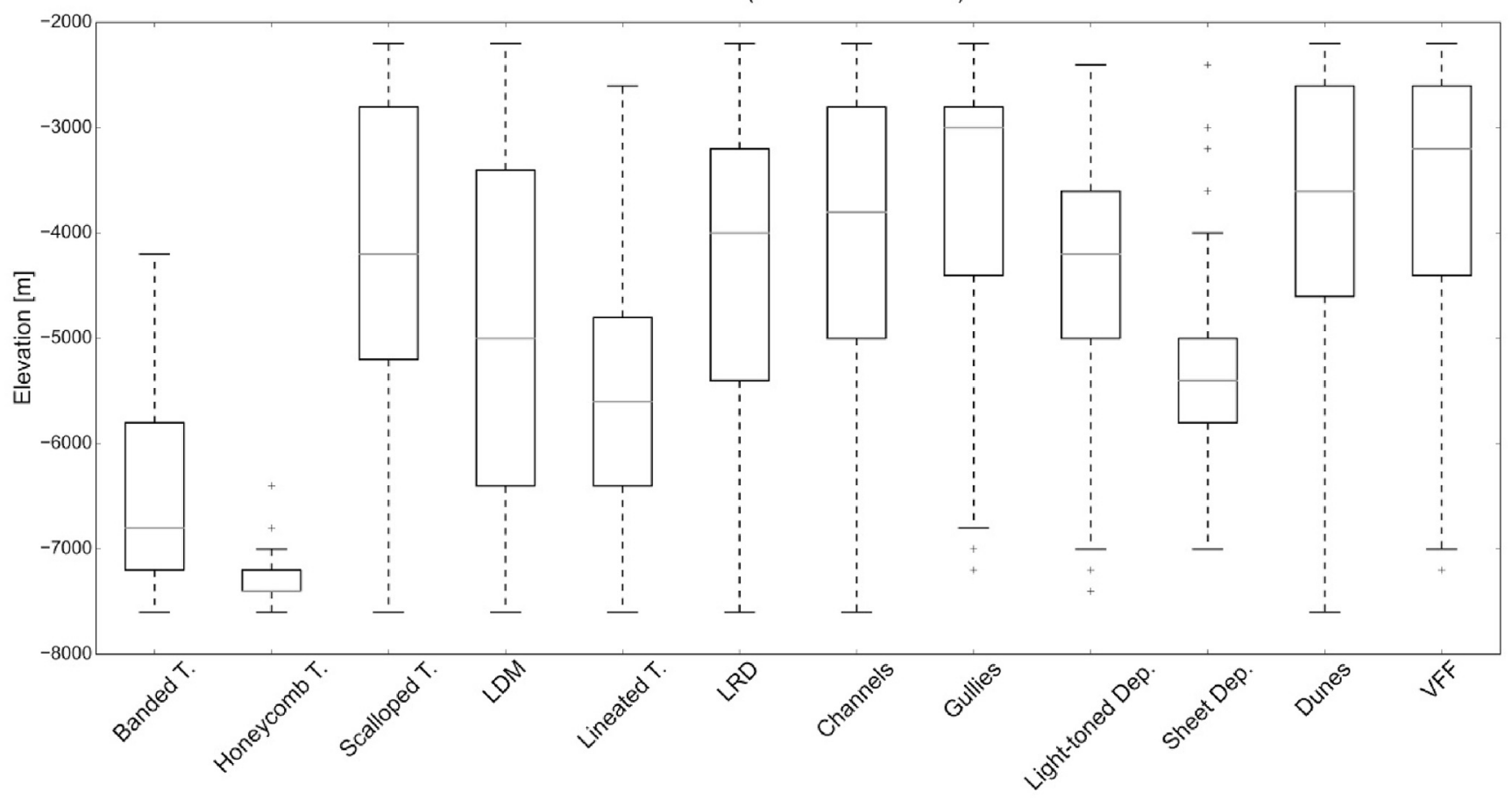

Fig. 8. Box-Whisker plot showing the relative distribution of landforms regarding their elevation. For explanation of symbols see caption of Fig. 5. 
Slopes (Absolute Occurence)

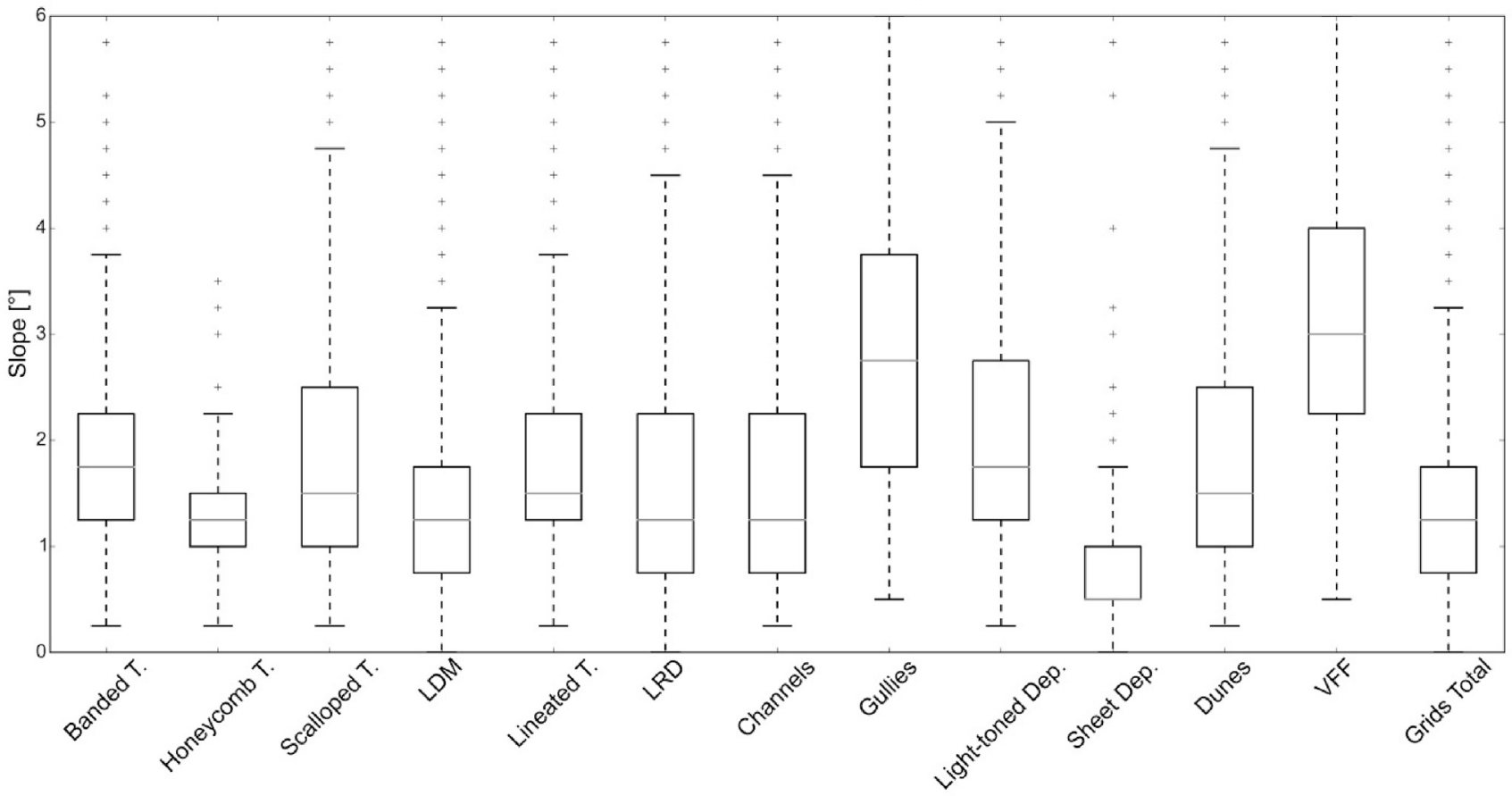

Fig. 9. Box-Whisker plots showing the distribution of landforms regarding their absolute slope. For explanation of symbols see caption of Fig. 5 .

during the Hesperian. Furthermore, they hypothesized that these LTD might have been deposited as a delta in a subaqueous environment. Just north of Hellas, Salese et al. (2016) studied phyllosilicate-bearing intercrater plains that suggest a wet and depositional milieu during the Noachian. They also calculated relatively high erosional rates of these deposits $\left(\sim 1000 \mathrm{~nm} / \mathrm{yr}^{-1}\right)$, suggesting an ancient sedimentary cycle in the northern Hellas region. During the Hesperian, these sediments have been partially covered by younger volcanic deposits (Salese et al., 2016).
Another extensive area within Hellas suggesting a former aqueous environment is located along Hellas' western rim, and consists of poorly hydrated crystalline silica (Bandfield et al., 2015). Hence, at least northern and western Hellas experienced an intense period of aqueous activity during the Noachian, causing the formation of phyllosilicates.

Based on the mapping in this study, LTD such as those observed in Terby crater appear to be part of an extensive sedimentary belt extending up to $1000 \mathrm{~km}$ along Hellas' NE rim (Fig. 18). An even wider extent

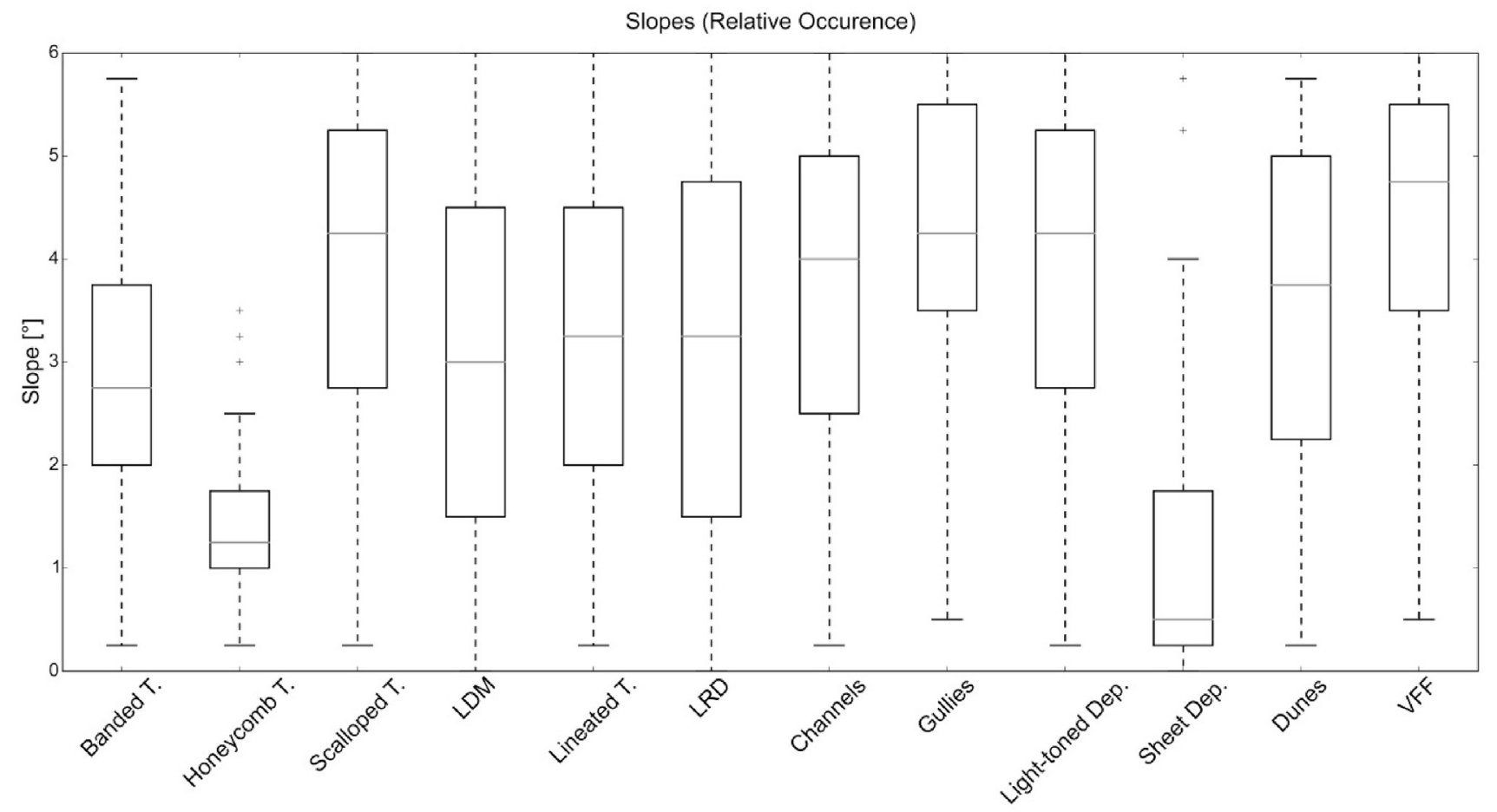

Fig. 10. Box-Whisker plot showing the relative distribution of landforms regarding their slope. For explanation of symbols see caption of Fig. 5 . 
Dust Cover Index (DCl) (Absolute Occurence)

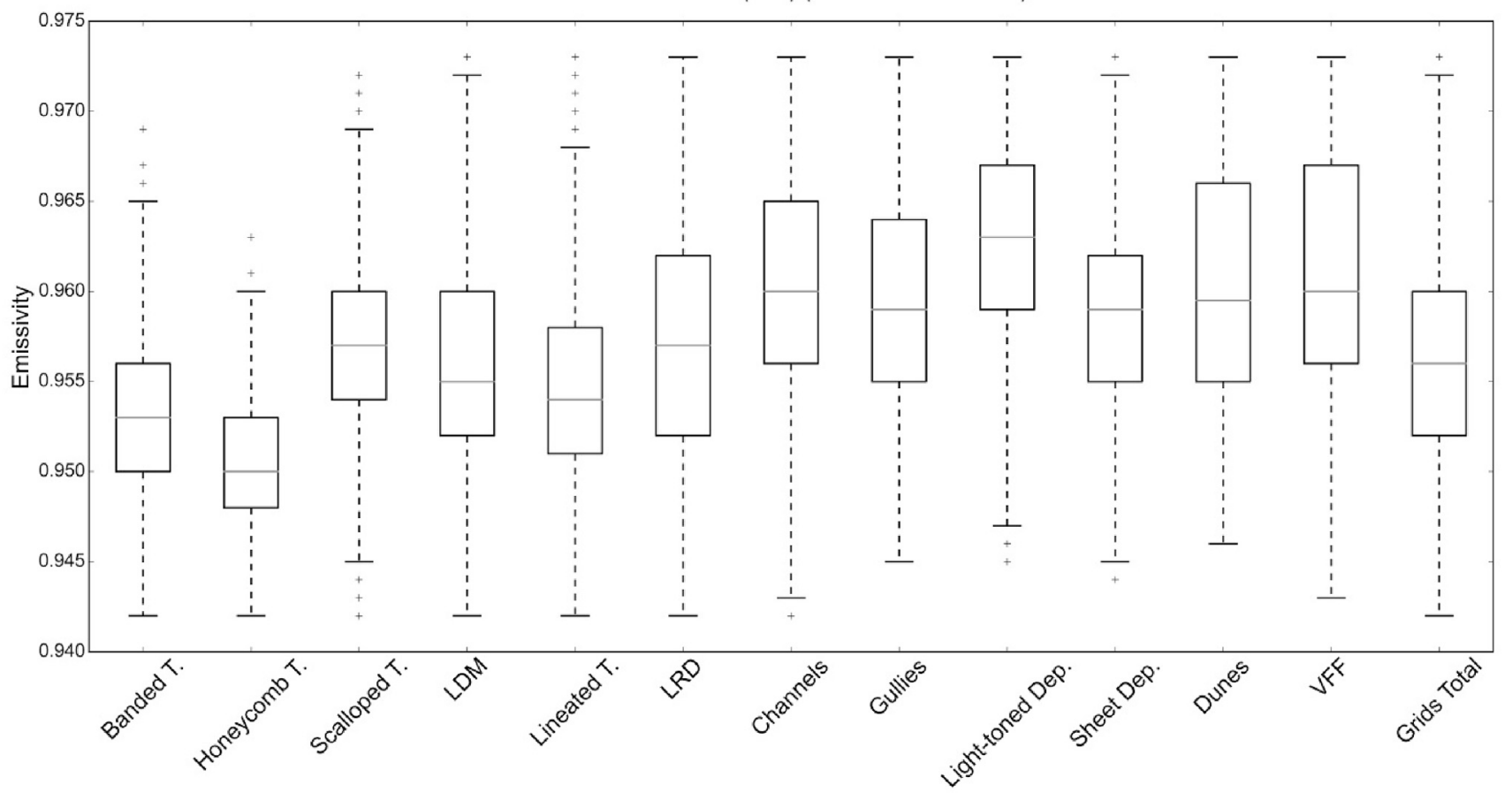

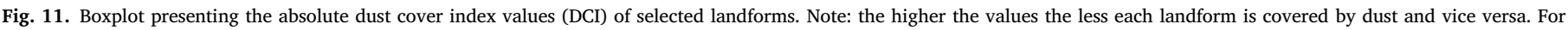
explanation of symbols see caption of Fig. 5.

cannot be excluded, as such deposits can only be identified if there are exposed outcrops visible. Other possible LTD deposits along the rim can be found in the Hellespontus Montes region along the western rim. On the floor of Hellas there are some further scattered occurrences; especially in an unnamed crater SW of Beloha crater. Most of the LTD are located at an elevation between -5000 and -3500 m (Figs. 8 and 20).
They tend to occur on steeper slopes with inclinations of $3^{\circ}-5^{\circ}$ (Fig. 10). The aspect distribution shows a strong peak towards SW, which is likely due to the extensive sediment bank on the inner slope in NE Hellas. In THEMIS nighttime IR data, LTD show a significant trend to high TI values. They are generally characterized by a very low dust cover (Fig. 12).

Dust Cover Index (DCl) (Relative Occurence)

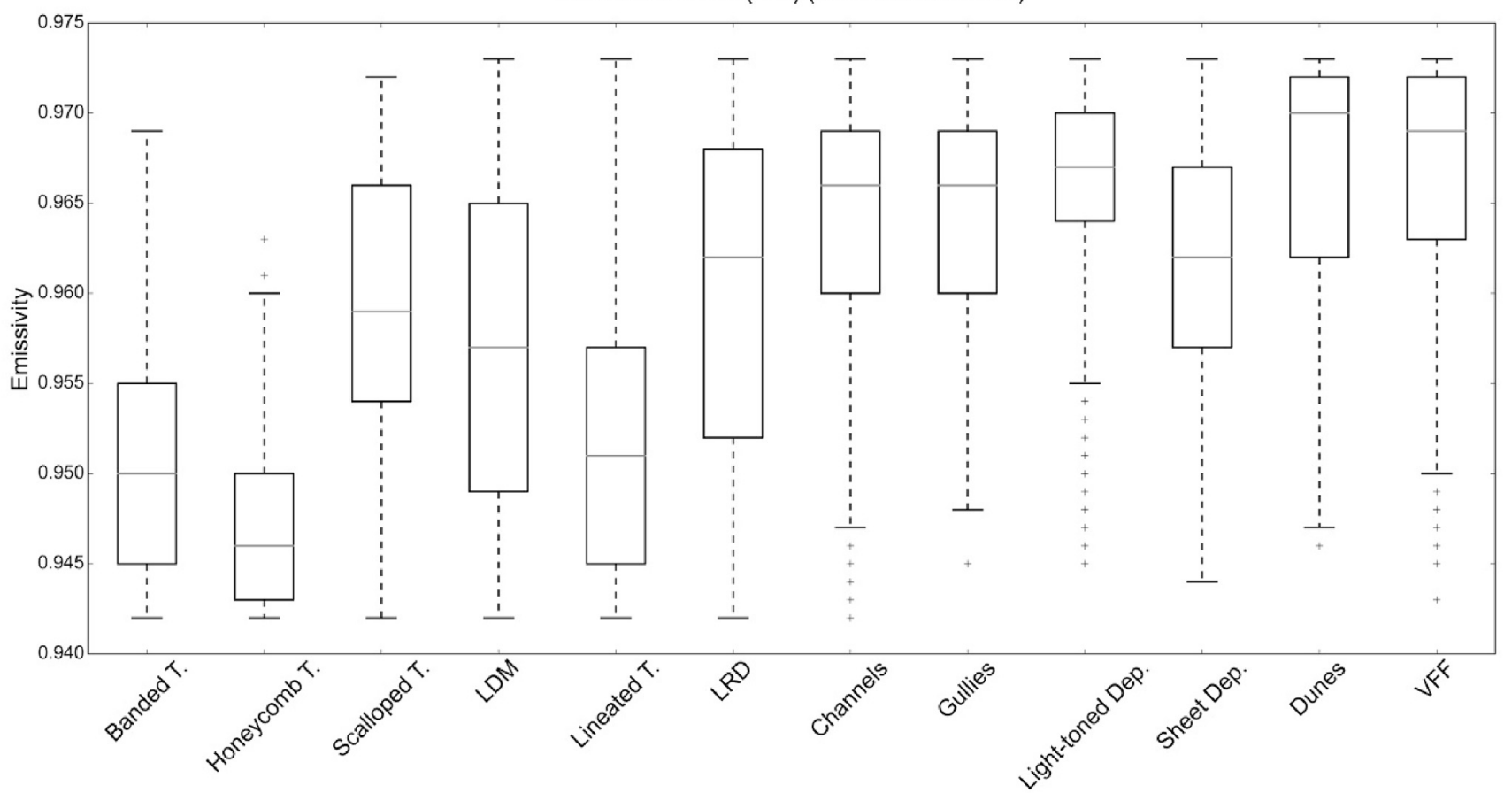

Fig. 12. Box-Whisker plot showing the relative distribution of landforms regarding their DCI. Note: the higher the values the less each landform is covered by dust and vice versa. For explanation of symbols see caption of Fig. 5. 


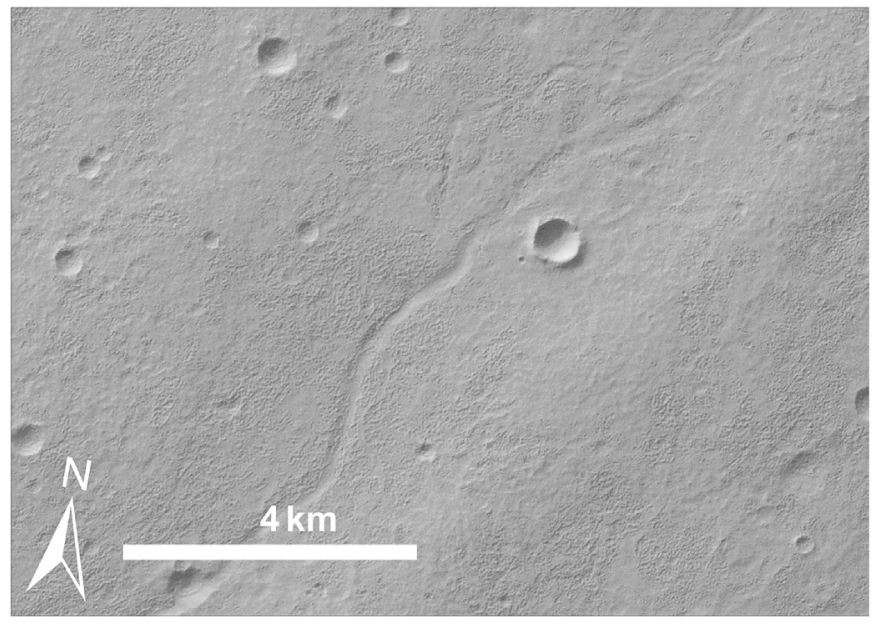

Fig. 13. Muted and dissected terrain north of Dao Vallis (CTX image P19_008426_1440 at $\left.35.7^{\circ} \mathrm{S}, 83.9^{\circ} \mathrm{E}\right)$.

The high-resolution mapping of the entire Hellas basin was also used to identify possible ancient shoreline relicts in Hellas, which were suggested by Moore and Wilhelms (2001). They described at least one continuous scarp encircling the inner basin, and hypothesized it being the remnant of an old shoreline of a possibly ice-covered lake.
Our mapping has not shown clear evidence for an old shoreline. Their geomorphic expression may either be too weak due to erosion, or there may have never been a body of water within Hellas. We only found two locations on the floor of the basin where possible shorelines may suggest that at least small lakes existed on the lowest parts of Hellas Planitia (Fig. 19). The amount of grids containing possible coastal morphologies was too small for statistical analysis $(n=19)$, thus we excluded them from our plots and maps.

Gullies are considered to be small and very local source-channel-fan systems. The length of typical gullies rarely exceeds $1000 \mathrm{~m}$; their width ranges from several meters to a few decameters. They are found on steep, predominantly pole-facing, slopes, especially on crater walls or mountains, ranging from $24^{\circ}$ to $30^{\circ}$ inclination. They are mainly found in the Martian mid-to-high latitudes between $30^{\circ}$ and $72^{\circ}$ latitude (Harrison et al., 2015). First described by Malin and Edgett (2000) on basis of high-resolution MOC imagery, they were interpreted to be the most likely examples for possible liquid water activities on recent Mars, and thus, of high importance for potential astrobiological habitats. Today, there are three prevailing formation models; a wet, water-based origin, suggesting that either subsurficial water or melting ice formed gullies fluvially (e. g. Malin and Edgett, 2000; Christensen, 2003; Harrison et al., 2015), a CO2-based origin (e. g. Cedillo-Flores et al., 2011; Diniega et al., 2013; Dundas et al., 2015b), and simple gravitational dry mass movements of eolian sediments (Shinbrot et al., 2003; Treiman, 2003).

The density of gully distribution in Hellas is low compared to the

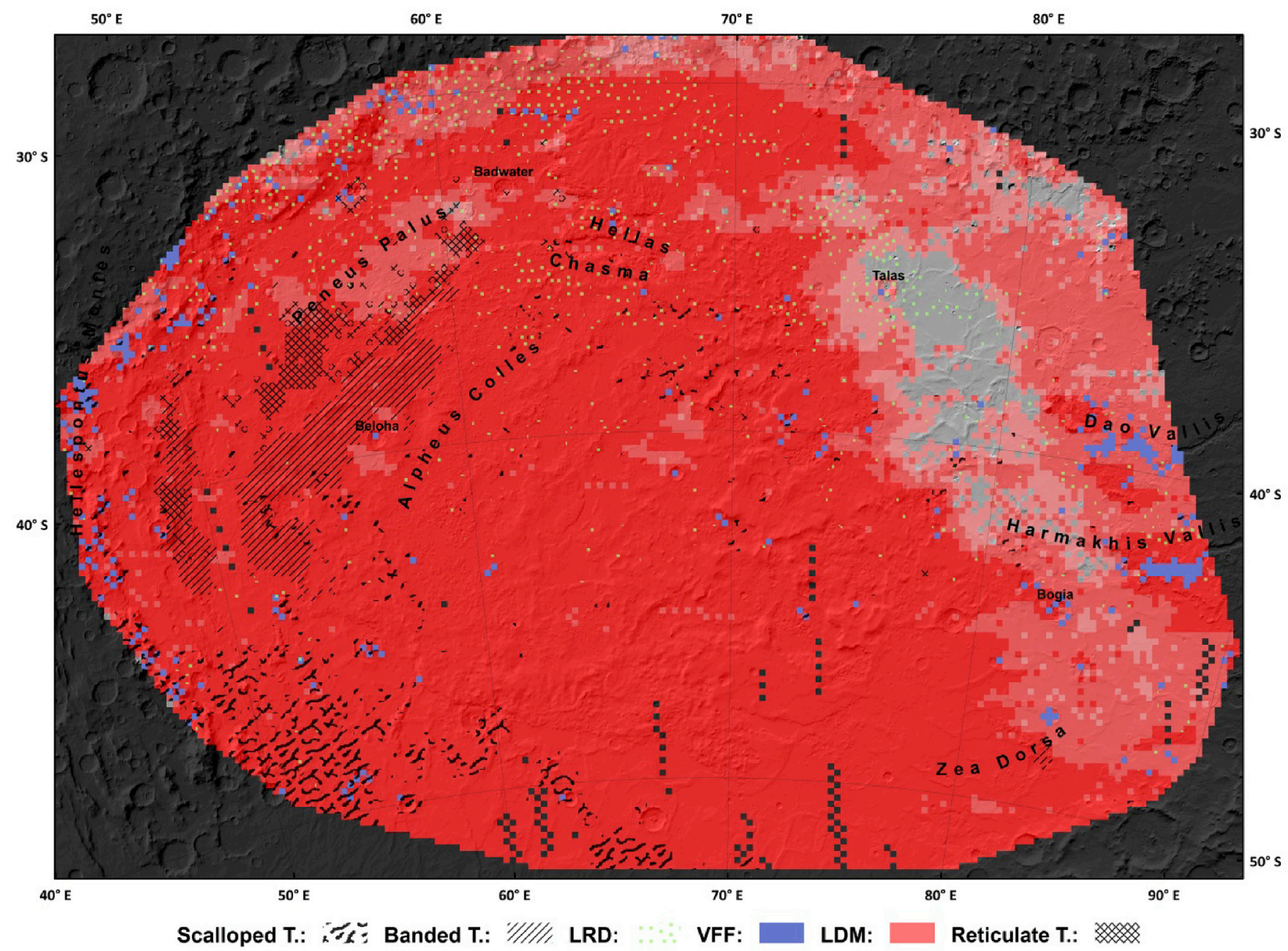

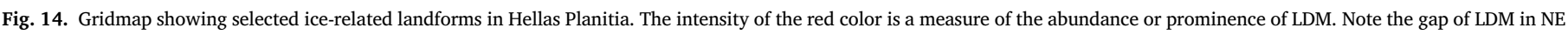
Hellas. Basemap: MOLA. (For interpretation of the references to colour in this figure legend, the reader is referred to the web version of this article.) 


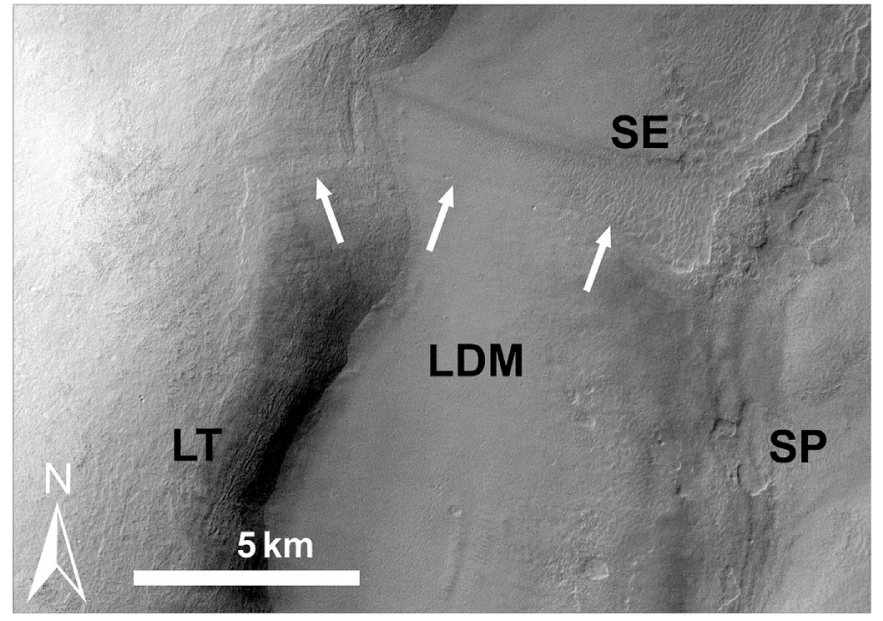

Fig. 15. Various morphologic expressions of LDM in Hellas. To the left there is the stratigraphically oldest LDM layer termed lineated terrain (LT), showing linear patterns. The scalloped terrain occurs in two different types: the classic pitted and ovoid form (SP) and a more diffusively distributed form (SE). SP appears to be predominantly controlled by insolation and SE by wind activities (white arrows). Note the ramp of the ridge in the upper left part of the image, where probably aeolian wind streaks are passing through (CTX image P14_006528_1412 at $38.8^{\circ} \mathrm{S}, 69.7^{\circ} \mathrm{E}$ ).

surrounding highlands of the southern mid-latitudes (Harrison et al., 2015, Fig. 18). In this respect, the topographically low Hellas basin is similar to the northern lowlands, which also have a low gully density (Harrison et al., 2015). Within Hellas Planitia, most gullies were observed along the western, northern, and eastern rim as well as the southern basin floor. Gullies are mainly found along scarps or attached to the inner walls of medium-to large-sized craters. However, craters of a given size can display very different gully densities, e.g. in Bogia crater (75 km diameter) we determined a high density of gullies, but in a similar-sized crater not far to the west of Bogia no gullies could be found. Even at Badwater crater, the lowest point on Mars, no gullies have been observed at CTX resolution. Other landforms displaying gully erosion are outcrops of light-toned deposits and LDM-covered mountains and hills. Despite of the low elevation of Hellas, there is much fewer gully activity than expected. Our results show that gullies preferentially appear at higher elevations of $>-4000 \mathrm{~m}$ (Fig. 8). In Hellas, most gullies occur on pole-facing slopes with high inclinations (see Figs. 10 and 22); but it has to be noted that our slope values are averaged for $20 \times 20 \mathrm{~km}$ grids, which is too coarse to resolve the local slopes of gullies. Nevertheless, there seems to be a slight preference for gullies being located on

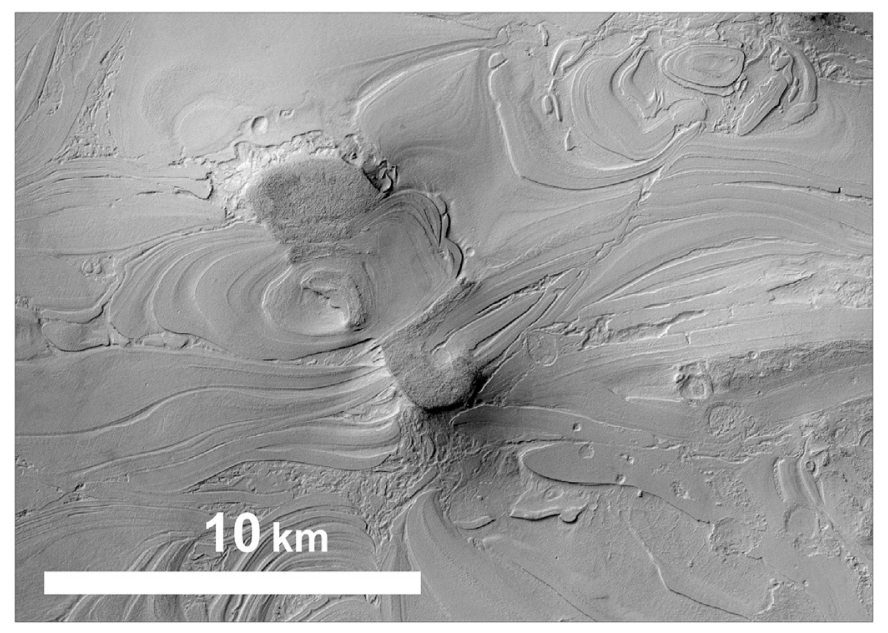

Fig. 16. Banded terrain in the Alpheus Colles region (Cropped CTX image P17_007636_1414 at $\left.38.9^{\circ} \mathrm{S}, 55.7^{\circ} \mathrm{E}\right)$.

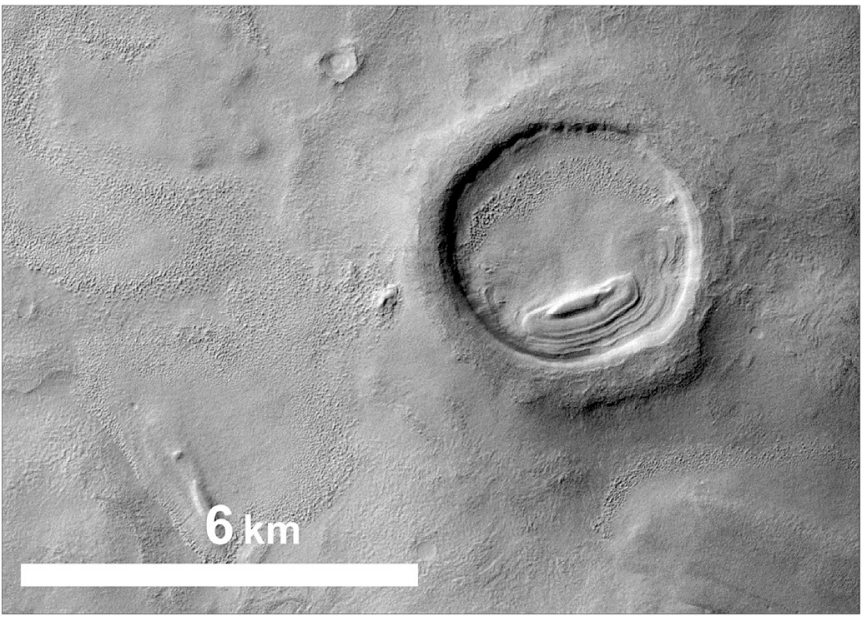

Fig. 17. Crater filled with layered-remnant deposits (LRD). In the left part of the image, a younger, but marginally textured LDM is embedded into an older LDM layer (detail of CTX image P18_008084_1461 at $35^{\circ} \mathrm{S}, 61.8^{\circ} \mathrm{E}$ ).

pole-facing slopes even at large scale. Moreover, grids containing gullies show a strong shift towards higher TI values, in agreement to observations done by Harrison et al. (2015). There is no correlation with respect to the DCI.

Sheet deposits are extensive, thin (meters to tens of meters thickness), and high-thermal inertia deposits covering areas with gentle slopes (Fig. 21). There are two possible origins of this landform: volcanic and/or fluvial. Lava sheet flows show a very rough, folded, and/or undulating texture, and are also interpreted as inflated lava flows (Zimbelman et al., 2011; Leverington, 2011). Alternatively, they might also be of fluvial origin. In this case, they show a smooth and even surface and appear interconnected to channels. Voelker et al. $(2013,2017)$ described them as possible cryofluvial sediment flows. Thus, these sheet deposits would be the sedimentary remnants of ancient floods.

Most sheet deposits occur on the floor of Hellas Planitia close to its rim and channels (Fig. 18). There are prominent examples along the banks of the big eastern outflow channels of Hellas, but also in Peneus Palus. Most of these deposits are located at an elevation of -6000 to $-5000 \mathrm{~m}$ within gently inclined and SW-exposed grids (Fig. 8). In THEMIS data, they exhibit a strong trend toward high TI values. Grids containing sheet deposits show a thin dust cover according to DCI data (Fig. 12).

\subsection{Other landforms}

The honeycomb terrain is a unique landform on Mars and only occurs on the bottom of Hellas Planitia close to the lowest elevations of the planet. It is characterized by cell-like depressions that are separated by narrow ridges. Several hypotheses have been proposed to explain the formation of this peculiar landform. Moore and Wilhelms, 2007 suggested that these features might be imprints of grounded icebergs, molding these forms into the sediments. Mangold and Allemand (2003) hypothesized their evolution by endogenous convection cells. Salt diapirism (Mangold and Allemand, 2003; Bernhardt et al., 2016b) and ice diapirism (Weiss and Head, 2017) have also been proposed.

The honeycomb unit is only observed in the Peneus Palus region. We could not find any other evidence for honeycomb terrain in Hellas region. Honeycomb terrain is located along the transition zone between Peneus Palus and Alpheus Colles, and predominantly occurs on extremely low elevations of $-7000 \mathrm{~m}$ or less and on gentle slopes ranging between $1^{\circ}$ and $2^{\circ}$ (Fig. 10). It occurs mainly on slopes with aspects towards SE and NW. THEMIS data do not show a trend of grids containing honeycomb terrain towards low or high TI values. However, in DCI there is a strong trend towards a thick dust cover (Fig. 12). 


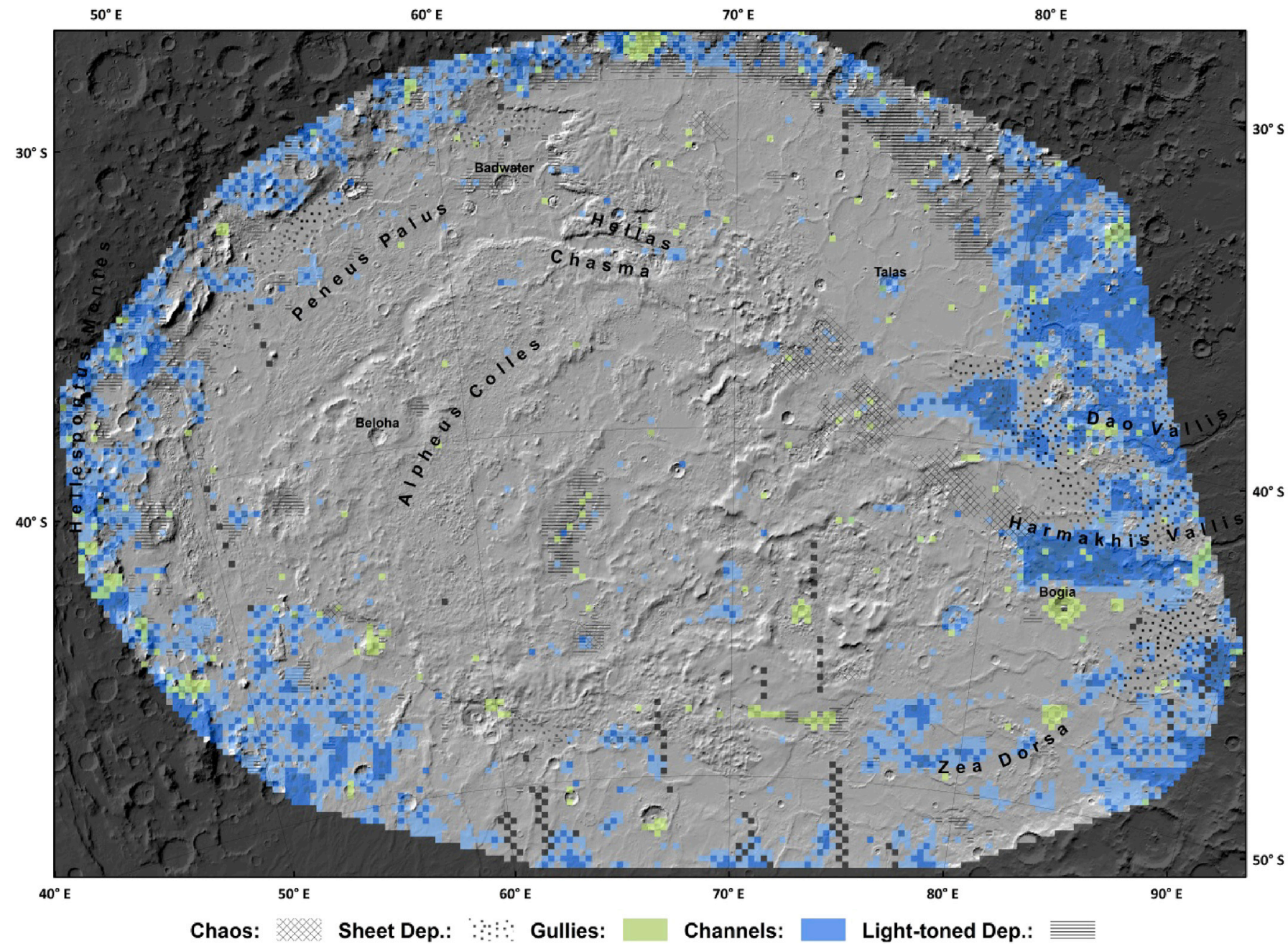

Fig. 18. Gridmap showing the geography of potential water-related landforms (basemap MOLA).

Because of its enormous depth, and hence, its dense atmosphere the investigation of dunes in Hellas Planitia is of special interest. The formation of dunes requires a source area, a sufficient amount of lose

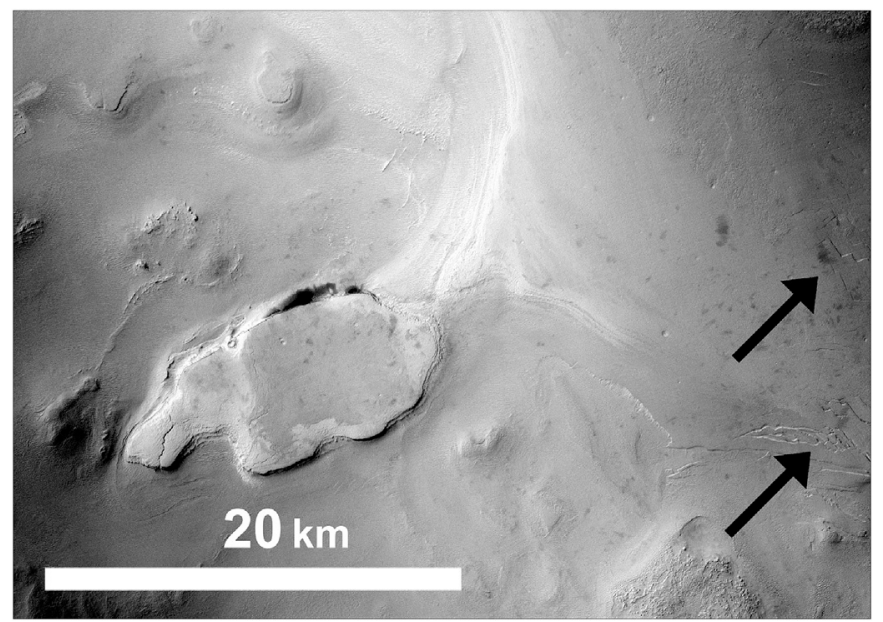

Fig. 19. Light-toned deposits in a nameless crater on the western Hellas floor. The crater floor show extensive sedimentary bodies, obviously having a brittle behavior (note the young cracks and troughs indicated by black arrows). The curvilinear structure in the right part of the image might also be an ancient shoreline formed by wave refraction worth for discussion (CTX image P14_006700_1386_XI_41S306 W at 41.1 ${ }^{\circ} \mathrm{S}, 53.2^{\circ} \mathrm{E}$ ). material, and an active wind regime. On Mars, dunes preferentially occur in topographical depressions such as impact craters or valley floors, but also around the north polar cap. However, the Mars Global Digital Dune Database (Hayward et al., 2014) shows a scarcity of dunes for the Hellas region. Most dunes on the planet are of mafic composition, suggesting that they have a similar origin (Tirsch et al., 2011). An intracrater dune field on the southern basin floor of Hellas Planitia was studied by Tirsch et al. (2011), who found spectral evidence for pyroxenes.

In Hellas Planitia, most dunes occur south of $40^{\circ} \mathrm{S}$ in impact craters and other topographic lows. There is one extensive dune field in Hellespontus Montes on the rim of Hellas. Surprisingly, there are almost no dunes in the deepest parts of the basin, e.g. in Peneus Palus. Most dunes appear at elevations higher than $-5000 \mathrm{~m}$ (Fig. 8). Regarding slope inclination, dunes mainly occur on inclinations of $2^{\circ}-5^{\circ}$. Most of the grids containing dunes are exposed to the southeast. THEMIS IR data has a relatively high dispersion, while DCI data shows a tendency towards low dust coverage (Fig. 12).

\section{Discussion}

The focus of this study was to analyze landforms involving water and/ or ice in the deepest basin on Mars. Hellas Planitia is among the places with the highest likelihood for the transient existence of liquid water and ice, making it a vital study area. Based on our results we demonstrated that Hellas contains a substantial diversity of landforms. By applying the newly developed grid-mapping method we derived quantitative 


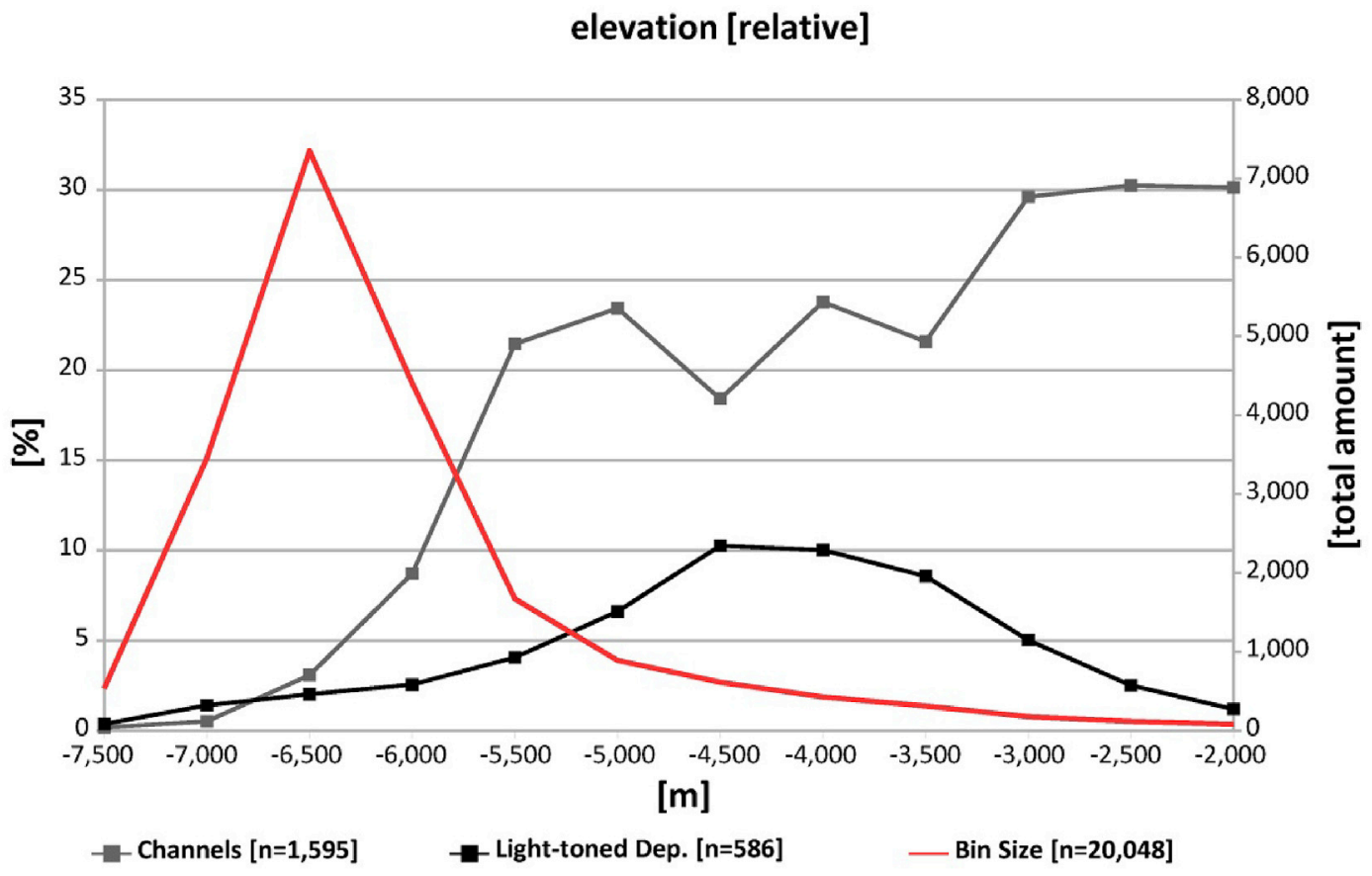

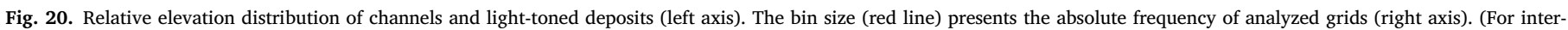
pretation of the references to colour in this figure legend, the reader is referred to the web version of this article.)

information about the distribution of these landforms. The following discussion puts the results of the most important landforms into context, in order to document the historic and present-day environment of Hellas Planitia.

\subsection{Ice-related landforms}

Hellas Planitia is located within the southern latitude-dependent mantle belt (Schon et al., 2012). Despite most of Hellas is covered by LDM, our results show an extensive gap of LDM in the northeastern part of the basin. Subsequently, we want to present possible climatic scenarios how this gap evolved. The dense atmosphere of the study area as well as high temperatures (Millour et al., 2015; Forget et al., 1999) are able to cause more intense winds (Greeley et al., 1980) and absorbing higher amounts of water than other more elevated regions of the planet (Weischet, 2002). Dense air (Kieffer et al., 1992) and high wind speeds (Siili et al., 1999) in Hellas condition transport/removal of solid particles as well as a higher

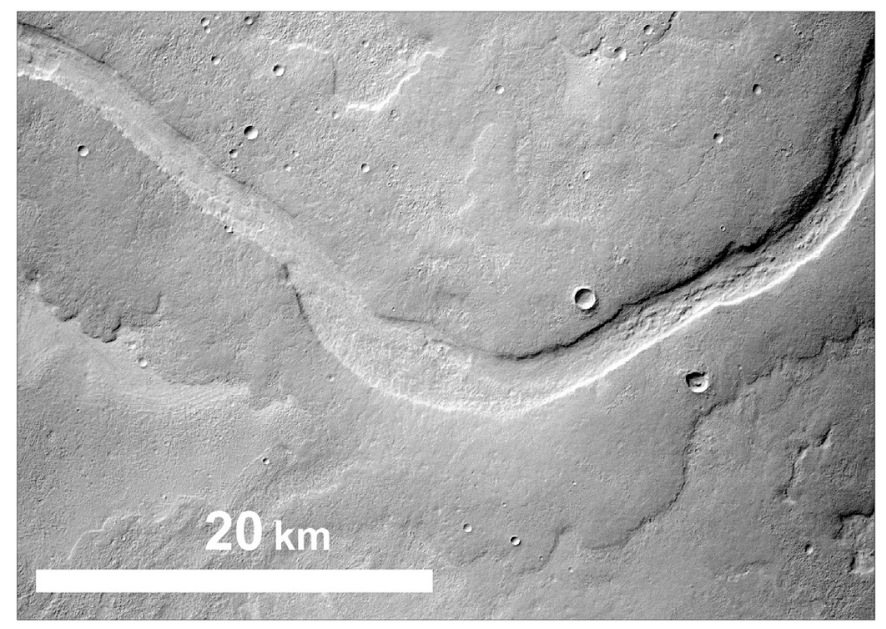

Fig. 21. Extensive sheet deposits covering the banks of the lower Dao Vallis region (Cropped CTX image P19_008492_1423 at $39.9^{\circ} \mathrm{S}, 81.4^{\circ} \mathrm{E}$ ). absorption of water. Both processes are important factors in eroding and/or subliming LDM.

The most important evidence for sublimation of LDM is the scalloped terrain and the rough texture on its surface; both are likely the result of ice removal. There are three extensive areas in Hellas where LDM is either strongly textured (i.e. degraded) or not existent:

The highly textured LDM north of $\sim 35^{\circ} S$ is probably the result of changing solar insolation caused by the variable obliquity of Mars' rotational axis (Laskar et al., 2004). Today, solar insolation, and hence, temperatures, are higher in the northern part of Hellas as compared to the southern part (Millour et al., 2015; Forget et al., 1999), leading to an increased degradation of the LDM in northern Hellas. We assume that the highly textured LDM in northern Hellas is the remnant of an older LDM layer that has been deposited during earlier high obliquity excursions, when the temperatures at these latitudes where significantly lower.

An inclined area at the southwestern inner rim of Hellas displays LDM which appears both significantly textured and scalloped. This region is located adjacent to a wide gap of the rim called Malea Planum, connecting the Hellas basin to the south polar highlands. According to existing wind circulation models (Ogohara and Satomura, 2008; Howard et al., 2012) winds drain through this southwestern gap towards north and into Hellas. Siili et al. (1999) and Howard et al. (2012) suggest that these winds might be caused by polar air masses moving down into Hellas Planitia by katabatic processes. The high wind speed at this inclined gap may be able to remove the protecting surface lag of the LDM (Head et al., 2003), and hence, facilitate the sublimation of the ice content of the LDM resulting in a rough texture.

The wind circulation models for Hellas might also explain a complete gap of LDM in NE Hellas (Fig. 14). The winds originating from the south polar highlands are rotating clockwise within Hellas (Howard et al., 2012). When they have reached the northern rim of Hellas, they first turn east, and later south again. We hypothesize that these air masses heat up at the northernmost part of Hellas, due to the higher solar insolation at these latitudes $\left(<35^{\circ} \mathrm{S}\right)$, before they move south again. The high temperatures cause a decline of the relative humidity, advancing desiccation of soils. The area in NE Hellas where these dry air masses would interact with the surface corresponds to the location of the gap of LDM. We assume that the dry air either eroded a former LDM blanket or completely 


\section{azimuth [relative]}

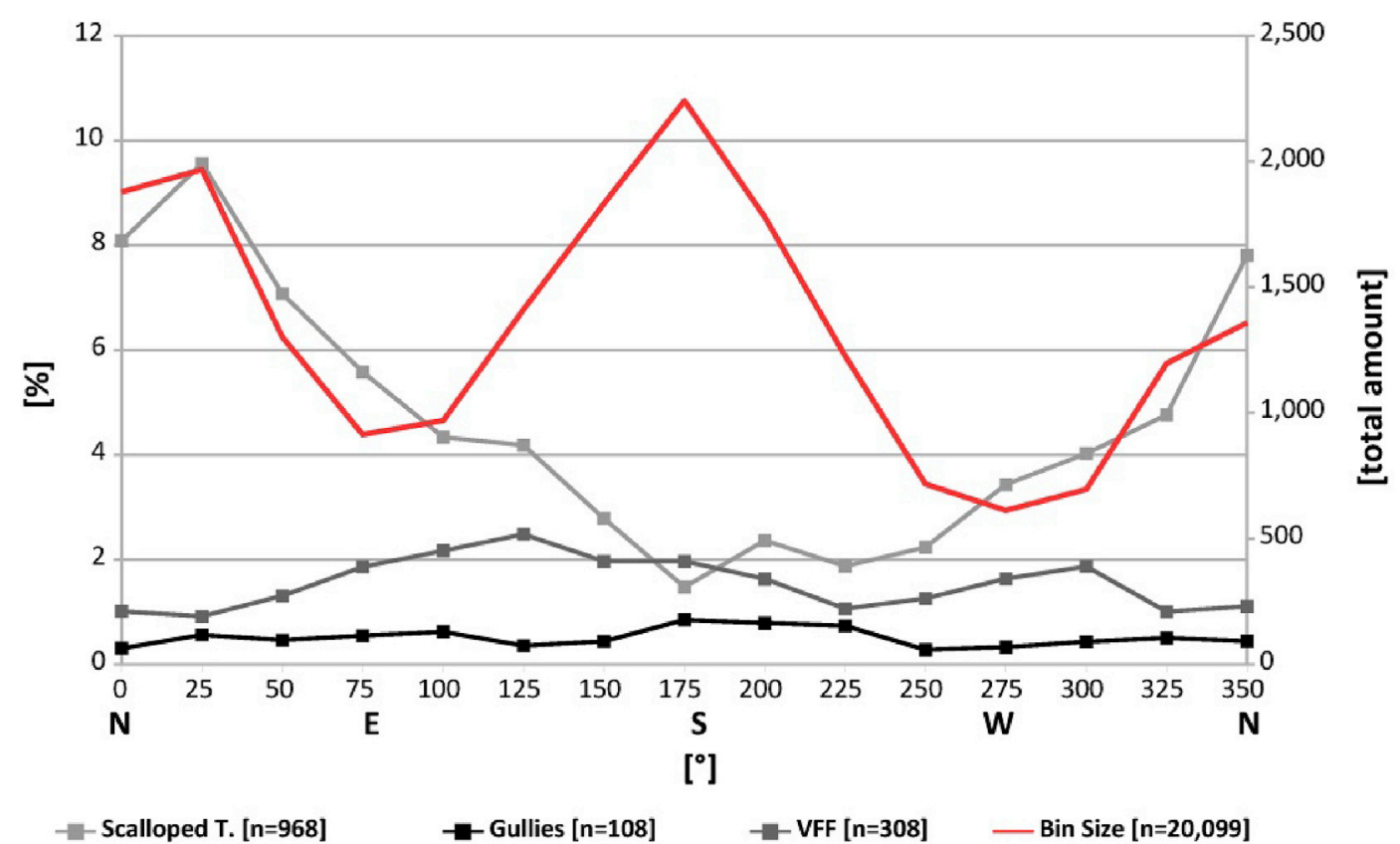

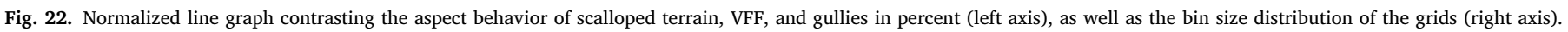

prevented its formation at this place.

In Hellas we found two different types of scalloped terrain located within LDM: (1) distinctive pitted depressions (SP in Fig. 15) and (2) an extensive rugged morphology like the scalloped depressions, however, at a much smaller scale and areally widespread (SE in Fig. 15). Based on their morphologies we assume that both morphologies have been evolved by the same process.

Following, we present evidences that the development of scalloped terrain not only depends on solar insolation but also on aeolian processes. They appear to be geospatially linked to regions with a strong wind regime. Moreover, their axes are often orientated along the wind direction.

Siili et al. (1999) calculated wind patterns on the southern slopes of Hellas and found evidence for very high wind speeds up to $30 \mathrm{~m} / \mathrm{s}$. The geospatial and geomorphic characteristics of scalloped terrain supports the hypothesis of wind currents originating from south polar highlands (Siili et al., 1999; Howard, 2000; Howard et al., 2012; Ogohara and Satomura, 2008; compare for discussion on LDM above); i. e., the longitudinal axes of the depressions are orientated into the direction of the wind, and not directly north toward the sun. Furthermore, the small ridges are also located transverse to the wind, similar to ripples. We suggest that these ripple-like ridges developed in a unidirectional wind regime. As the wind generally comes from the same direction it probably caused very shallow ridges in the loose material covering the surface, e.g. dust or the LDM itself. Thus, a small-scale relief of ripples could evolve. In turn, this relief caused little variations of the wind speed near the surface, and hence, different intensities of erosion. On top of these ripples the wind was most intense, and could erode LDM easier than in between. As a result, the protecting lag of LDM has been removed along the tops of ripples, and wind currents could excavate the volatiles beneath, especially along the side opposed to the wind, leaving transversal ridges behind. Similarly, the dominant wind direction may have been responsible for the deflection of the scallop orientation from N-S (expected if only insolation were responsible) to NW-SE, caused by a mixture of solar insolation and wind. As their steep side is located against the wind, the volatiles exposed at the steep scarp are subject to intensified degradation by wind-driven sublimation. There are dense populations of these deflected scalloped depressions and ridges in SW Hellas directly adjacent to the Malea Planum gap (Fig. 14), where strong unidirectional winds have been proposed (Siili et al., 1999; Howard et al., 2012).

On the other hand, no such scalloped depressions and ridges occur on similarly inclined slopes in SE Hellas, where the same northern exposition and amount of insolation is given. This leads to the idea that wind, besides solar insolation, may be a prominent factor in the development of the scalloped terrain in SW Hellas. This notion is consistent with other models suggesting an aeolian origin of the scalloped terrain (e.g. Costard and Kargel, 1995; Zanetti et al., 2010; Ulrich et al., 2010; Séjourné et al., 2011). Hence, strong winds (Siili et al., 1999) might have triggered or at least supported the removal of the dusty surface lag (Head et al., 2003) by aeolian erosion, and hence, entailing desiccation processes (Mustard et al., 2001), causing the development of the scalloped terrain.

The large-scale distribution of layered-remnant deposits (LRDs) within craters over all of Hellas Planitia appears to be controlled by a latitudedependent process, as they mainly occur north of $37^{\circ} \mathrm{S}$. On the other hand, their small-scale distribution remains paradox and difficult to explain. At local scale, they predominantly exist on the equator-facing wall of impact craters, i. e. on the part of the crater that receives the highest amount of solar insolation. However, if they consist of the same material as LDM, as proposed by Morgenstern et al. (2007), they would be subject to increased sublimation in relatively warm or dry local environments.

Although their large-scale distribution appears to be latitudedependent, our mapping suggests that the LRDs are more or less independent from the distribution of LDM, as they occur in areas with both thick and absent LDM cover. For example, they also occur in the region in NE Hellas that probably never has been blanketed by LDM (see discussion above on LDM). Besides the assumption that their evolution and composition is not linked to LDM, we suggest three different scenarios:

Enhanced aeolian processes might have caused sublimation and/or excavation of LDM material. But wind does not explain the consistent location of LRD in the southern half of craters over such a huge area, as the currents in northern Hellas are generally westerlies. If LRD were eroded by wind, they are expected to be located on the wind-protected western lee side of the inner crater bowl.

As they predominantly occur north of $37^{\circ}$, solar insolation, and 


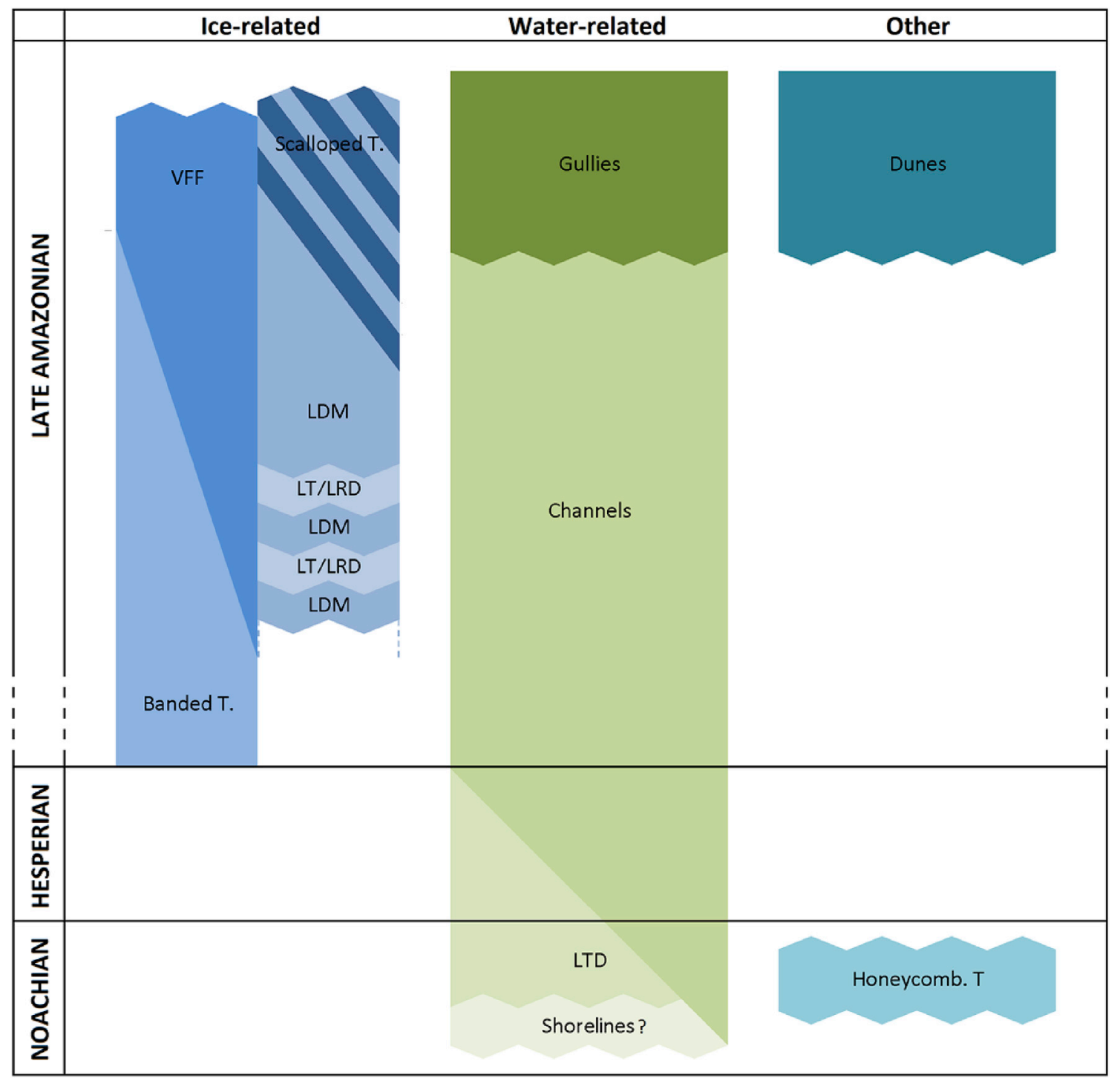

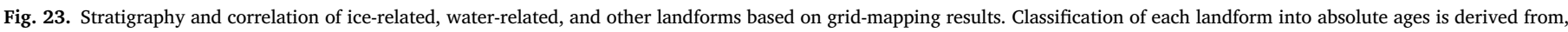
Bernhardt et al., 2016a (honeycomb terrain), Diot et al., 2016 (banded terrain), and Leonard and Tanaka, 2001 (channels and LTD).

hence, thermal sublimation, could explain the latitude-dependence of this landform. But it does not explain why LRD-layers consistently "survived" in the southern part of craters that (currently) receives the most intense solar radiation. This hypothesis might be conclusive if LRDs were located in the shaded northern half of a crater, where volatiles are protected of sublimation. Due to Mars' permanently changing obliquity of up to $47^{\circ}$ within the last $20 \mathrm{Ma}$ (Laskar et al., 2004), it is possible that the northern parts of the crater interiors once received a high amount of solar insolation even at these latitudes. Thus, any volatile-rich material could have been removed there.

Another explanation for this paradoxical location might be that LRDs are a result of relief inversion. In this scenario, today's LRDs were once hollows within a volatile-rich layer (LDM). The origin of the hollows might be caused by enhanced sublimation of a thin LDM layer draping over the topography of an impact crater. This would preferentially remove LDM in the southern half of the crater bowl, were the incoming insolation is highest, leaving a hollow. Subsequently, this hollow may have been refilled by a younger material poor of ice (e.g. dust). When the remaining LDM material around and beneath this younger material vanished later, it remained as a LRD in this crater. We assume the last two scenarios (or a combination of both) as the most likely ones, as only these scenarios can explain the continuous location of the LRDs within impact craters and their latitude-dependence.

Viscous-flow features (VFF) form by gravity-driven processes, so by definition they can only form in the presence of inclined topography (slopes). In Hellas, VFF seem to be absent at low elevations of less than about $-5500 \mathrm{~m}$, despite of the presence of relatively rough topography, and hence, slopes, on the basin floor (Fig. 2). The terrain of the floor may not be as steep as the surrounding rim, but there are also chasms (Hellas Chasma), chaotic terrains (Hellas Chaos), big craters (e.g. Badwater, Talas, Beloha), cliffs, tall mounds and peaks rising up to $1200 \mathrm{~m}$ above their surroundings, as well as extensive hummocky terrains with hills rising more than $300 \mathrm{~m}$ above the plains (Alpheus Colles). The question is then, why are there no VFF observed on the slopes of the deepest parts of Hellas? As discussed above, it appears possible that the high air pressure and wind activities at these low elevations are able to absorb even more moisture than at higher elevations, and hence, desiccate the regolith. These conditions may have prevented the development of VFF in Hellas.

A further observation indicates that VFF might be genetically linked to gullies. Van Gasselt (2007) already suggested such a relation, as VFFs might have been able to contain a sufficient amount of water necessary for the development of gullies. In Hellas, they often share the same locations too. Moreover, both preferentially appear on elevations higher than $-5500 \mathrm{~m}$ and steep slopes. Milliken et al. (2003) found that gullies 
and VFFs on the southern hemisphere also share the same poleward exposition; however, in Hellas Planitia their aspect values differ from each other: VFFs are mostly exposed towards $\mathrm{E}$ and $\mathrm{W}$, in contrast to the preferred aspect values of gullies, tending slightly towards S (Fig. 22). Both landforms rarely occur on highly insolated and, hence, warmer, north-exposed slopes. Whereas gullies are dominantly located on shaded south-facing slopes, VFFs mainly appear on slopes receiving medium solar insolation. Based on our $20 \times 20 \mathrm{~km}$ grid map resolution, gullies and VFFs probably do not occur on north-exposed slopes as ice may long have disappeared or may never have accumulated on these relatively warm slopes.

The banded terrain, so far only detected in Hellas, is hypothesized to be a mobilized viscous flow of an ice-rich material, similar to the VFF (Diot et al., 2014, 2016). Based on the analysis of HiRISE images it has been suggested that banded terrain represents near-surface ice deposits that are subject to viscous downslope flow (Diot et al., 2014, 2016). Our mapping results enabled us comparing the large-scale geographical distribution of the banded terrain and VFF. Based on our results both landforms display different characteristics regarding their elevation, slope inclination, and DCI. In contrast to VFF, the banded terrain occurs at much lower elevations and on shallower slopes. Moreover, the banded terrain has a higher dust cover; probably caused by its low elevation, and thus, higher atmospheric activities.

As VFF, a landform requiring volatiles, seems to avoid low elevations in Hellas, we assume that desiccating environmental conditions on the low-lying Hellas floor are caused by a dense and warmer atmosphere. However, banded terrain is also interpreted to be related to the deformation of ice-rich material and predominantly occurs at these lowest elevations (Diot et al., 2014, 2016). This observation presents a paradox, as one type of ice-rich landforms (banded terrain) occurs on the floor of Hellas, whereas another one (VFF) is lacking.

Putting all possibly ice-related landforms in context we suggest that several climatic cycles caused deposition and degradation of LDM, and hence, the formation of LT and LRD (Fig. 17). As both landforms often appear as layered features, each layer could be the result of one LDM episode. Most recently, the development of scalloped terrain is evidence for degradation of the LDM blanket. Scalloped terrain is hypothesized to be an early stage of the geomorphologic process eroding LDM that leads to the development of LT and LRD. Moreover, VFF and the banded terrain seem to be inactive today, as we could not detect any deformed craters on top of their lobes in Hellas.

\subsection{Water-related landforms}

Despite we found a high morphologic diversity of channels in Hellas Planitia, their general density in the study area is lower than expected. Besides the big outflow channels in the east (i. e., Dao and Harmakhis Vallis), we identified very young and extensive channel systems along the rim (e.g. Navua Valles), and older, more eroded or muted, short channel networks. The distribution of channels along the rim of Hellas Planitia provides information for three different environmental conditions for their development.

The big eastern outflow channels are comparable with other outflow channels on the planet triggered by volcanic activities resulting in the release of water. Their dimensions which require enormous water volumes might suggest theories of a former lake within Hellas (e.g. Moore and Wilhelms, 2001). However, the valleys have been determined of Hesperian/Amazonian age (Leonard and Tanaka, 2001; Crown and Greeley, 2007), hence, Hellas would have contained a lake at the same time. But this appears to be unrealistic as the Martian climate at this time was already too cold (Schuster and Weiss, 2005) and the atmosphere too thin, in order to maintain such an extensive and deep body of water.

Small and typically dendritic valleys are widespread along the rim. Because of their narrow and shallow profiles we assume they were probably unable to transport high amounts of water. Some of the small valleys, e.g. Navua Valles, show very pristine morphologies suggesting an
Amazonian age (Hargitai et al., 2017).

Along the southern rim the density of channels is very low, indicating that either climatic conditions prohibited their development at these (colder) latitudes, or these channels have been significantly eroded (e.g. by aeolian processes). Furthermore, a later superposition by other materials, e.g. volcanic deposits from the adjacent Malea Planum volcanoes (Williams et al., 2010) is also possible. The lack of channels on the basin floor is still unclear.

Extensive thin deposits (hereafter referred to as sheet deposits) on the floor of eastern Hellas are apparently associated with the big outflow channels. We suggest that they are either of volcanic or fluvial origin.

If they are of volcanic origin they might be deposits of magmatic sheet flows, similar to those in other big provinces of Mars (e.g. Tharsis or Elysium). If so, their likely source was Hadriacus Mons $\sim 800 \mathrm{~km}$ to the east, as there is no other obvious volcanic edifice in their vicinity. However, the surface of the sheet deposits in eastern Hellas lacks typical volcanic features like a platy-ridged morphology (Keszthelyi et al., 2004).

Another scenario suggests a fluvial genesis. Kostama et al. (2010) reported evidence for the extensive release of subsurficial ice-bearing layers around the head regions of the big outflow channels (e.g. Dao Vallis). These layers were covered, and hence, protected by younger volcanic and/or sedimentary layers probably originating from Hadriacus Mons. After then, subsurficial magmatic intrusions may have triggered the melting and runoff of these ice-rich layers. When the ice melted, this ice-dust mixture (together with the overlying volcanic layer) converted into a liquid mixture with a high amount of sediments and began moving downward towards the Hellas basin as a so-called hyperconcentrated sediment flow or debris flow (Costa, 1988). At this time, the morphologies of the outflow channels had not yet developed. Thus, the sediment flow covered extensive parts of the eastern Hellas floor and deposited widespread sheet deposits. When the flow continued, the relative amount of sediments decreased by two processes; first, the sediments from the eroded overlying volcanic layer in the channels' source region had been washed out and deposited first, and second by kinetic sieving processes. When the flow became clearer it turned from a depositional into an erosional mode, commencing to incise the channels into the sheet deposits themselves. Thus, the lower and much narrower parts of the big outflow channels might have evolved on the basins floor $(\sim 250 \mathrm{~km}$ north of Bogia crater). Moreover, it is likely that further sedimentary flows drained through these channels later, covering the banks of these valleys with additional layers of sheet deposits (Fig. 21).

The extensive sedimentary bank along Hellas' western to northeastern rim, consisting of light-toned deposits (LTD), has been mapped as a Noachian subdued cratered unit $\left(\mathrm{Npl}_{2}\right)$ as well as a Hesperian ridged plains unit (Hpr) by Leonard and Tanaka (2001). These authors interpreted the Noachian subdued cratered unit as a thin blanket of aeolian, fluvial, or possibly volcanic origin. The younger Hesperian unit was interpreted as volcanic flood material consisting of low-viscosity lavas (Leonard and Tanaka, 2001).

Ansan et al. (2011) and Salese et al. (2016) suggested a sedimentary origin for the layers along the northern Hellas rim of Noachian age. Our grid-mapping results based on high-resolution imagery supported the theories made by Ansan et al. (2011) and Salese et al. (2016) that these bright deposits would not be consistent with mafic lavas. OMEGA and CRISM spectra reveal extensive $\mathrm{Fe} / \mathrm{Mg}$ phyllosilicates deposits in this region (Carter et al., 2013). The observed phyllosilicates along the rim are evidence for water activity in Hellas during the Noachian, comparable to the sedimentary bank in the circum-Chryse Planitia region (Carter et al., 2015). As these sedimentary deposits are mainly found at an elevation ranging from -5000 to $-3500 \mathrm{~m}$ along the rim, this sedimentary bank might support hypotheses of a former sea within Hellas (Moore and Wilhelms, 2007).

We found two possible scenarios for this sedimentary bank. The area now occupied by the sedimentary bank might once have been the contact line between land and the hypothesized sea, and hence, an environment 
for deposition of aqueous sediments. A possible hypothesis for the formation of the sedimentary belt, are proximal alluvial deposits, formed allochthonously by the fluvial influx of water. Thus, both the water and sediments might originate from the adjacent highlands of Tyrrhena Terra. The deposits are only observed along Hellas' western to northeastern rim and some very scattered places in the research area. Along the southern rim there are no LTD visible, correlating with a low density of channels in the same area. This asymmetric distribution might be caused by different climatic conditions; in northern Hellas (at lower latitudes) the Noachian climate was probably warmer and wetter than on the much colder southern basin rim (at higher latitudes). Hence, less or no fluvial activities in southern Hellas prevented the deposition of sediments there. Moreover, we found no clear evidence of former shorelines supporting a submarine deposition of LTD (see below).

Alternatively, as LTD can only be determined when they outcrop, we cannot exclude an even wider extend of that sedimentary bank around Hellas. Salese et al. (2016) suggested that Noachian LTD in intercrater plains north of Hellas are covered by stratigraphically younger volcanic deposits of Hesperian origin. Related to the Hellas basin, there is clear evidence for Hesperian volcanic activities along its eastern and southwestern rim (e.g. Leonard and Tanaka, 2001); i. e. sections completely lacking LTD.

Our results have shown that there are no obvious shoreline morphologies along the rim of Hellas, which could indicate an extensive and long lasting body of water as suggested by Moore and Wilhelms (2001). If there was indeed a body of water, it may not have existed long enough to form distinct coastal morphologies, or such easily degradable morphologic signatures may have been eroded over the last $\sim 3 \mathrm{Ga}$.

However, there is evidence for possible shorelines in association with LTD in small closed depressions at low elevations on the floor of western Hellas, (Fig. 19), e.g. in two craters northeast and southwest of Beloha crater. The southwestern crater shows arcuate lineations behind a sedimentary obstacle typical for littoral erosion morphologies caused by wave refraction (Panizza, 1996). The waves of a hypothesized lake might have eroded the sedimentary layers, which were deposited in the crater when lake level was higher. Moreover, Fig. 19 shows some cracks in the uppermost layer on the far right. This might be a hint that a material in the subsurface (water?) has been removed, causing contraction or even lateral movement downslope. Most of these fissures appear to be recent, as their edges are still pretty sharp. Therefore, an alternative hypothesis to a Hellas-wide paleo-sea is that Hellas might have hosted at least some smaller lakes.

Although gullies are relatively rare and scattered on the basin floor, they are still of significance. They mostly occur in craters of almost every size in that area. However, whereas some craters display gully morphologies, other similarly-sized craters nearby do not display them (e.g. compare $37 \mathrm{~km}$-diameter Bogia crater with an unnamed crater of comparable size about $150 \mathrm{~km}$ to the west). Bogia appears to be younger and has a high density of gullies all around its rim; in contrast, not a single one evolved in the older unnamed crater.

Although there is sufficient topographic relief energy on the basin floor (Fig. 2), gullies seem to avoid low elevations similar to the VFF, consistent with our hypothesis of low humidity values, and hence, desiccated soils in Hellas (see discussion above about VFF). This observation is also consistent with theories that gullies are formed by processes involving volatiles, whereas it is inconsistent with hypotheses that gullies form by gravitational mass movements (e.g. Shinbrot et al., 2003; Treiman, 2003).

Treiman (2003) observed that gullies occur on all substrates, slopes, and terrains of all ages. Together with the abundance of aeolian sediments and wind circulation patterns, both Shinbrot et al. (2003) and Treiman (2003) postulate that gullies consist of aeolian sediments formed by gravitational granular flows. But this hypothesis opposes our observations in Hellas. We found significant evidences that gullies prefer or avoid certain environments regarding elevation, slope and aspect. Applying the results of Treiman (2003) to Hellas, we would expect a high density of gullies within the basin. Its dense atmosphere and high wind activities make it a perfect trap for aeolian sediments. However, we could not detect a high density of gullies in our study area.

In summary, most of the channels and LTD formed during the Noachian and Hesperian, there are also some apparently young Amazonian channels along the rim of Hellas. They are characterized by young and distinct fluvial morphologies like braided channels, bars, or deltaic deposits (Hargitai et al., 2017). The most recent fluvial landforms in the study area are gullies of late Amazonian origin.

\section{Conclusions}

Grid-mapping is a very useful method to quantify the distribution of multiple small-scale landforms over wide areas, combining mapping with statistical analyses. We applied this approach to map the distribution of possibly water- and ice-related landforms over the entire Hellas basin at CTX scale, using a $20 \times 20 \mathrm{~km}$ grid. Although 24 different landforms were considered, only 15 of them are significantly abundant in Hellas. In particular, the Latitude-Dependent Mantle (LDM) was found to be widespread. However, a distinct region in the NE of Hellas was found to lack the otherwise dominant LDM cover. We found that the LDM distribution in the basin not only depends on latitude, but also on the pattern of wind circulation. Clockwise-rotating winds that enter Hellas in the SW and get successively warmer and drier as they move north- and then eastwards are hypothesized to cause the preferential sublimation of LDM in the northeastern part of Hellas. Alternatively, the winds may even have prevented the deposition of the LDM at these locations.

Similarly, the distribution and orientation of scalloped depressions appears to be controlled by wind. Scalloped terrain predominantly occurs where winds are strong. This observation supports hypotheses that the formation of scalloped terrain not only depends on solar inclination, but on aeolian processes, too. In contrast, the spatial distribution of layered remnant deposits on north-facing inner walls of impact craters in northern Hellas does not seem to be controlled by wind. Instead, their survival in these local niches may be a result of latitude-dependent solar inclination and/or processes resulting in relief inversion.

Despite the relatively high relief energy on the floor of Hellas, viscous flow features (VFF) are scarce. This may also be a result of high atmospheric pressure, hence, the exsiccated soils caused a prevention of the VFF development at low elevations. Besides, we noticed that VFF, are found on steep slopes with a relatively high solar insolation along the rim. But this higher solar inclination on slopes might even support the exsiccation of most slopes on the floor Hellas too, enhancing the lack of VFFs there. Analyzing the characteristics of the so-called banded terrain we could not find sublimation features on top of this landforms or a similar geographical behavior to other viscous-flow features observed in Hellas.

Three different types of fluvial landforms are present in Hellas: (i) large outflow channels, (ii) dendritic valley networks, and (iii) apparently very young Amazonian channels. The density of the dendritic valley networks varies along the rim, causing an asymmetric distribution. The lowest density is found at the southern rim, suggesting latitudedependent climatic conditions. As a result, the development of channels was more difficult at the higher and colder southern latitudes. A further landform we assume to be linked to fluvial activities are the socalled sheet deposits which seem to be related to the large outflow channels in the eastern part of Hellas. We suggest these deposits are caused by the big outflow channels as former hyperconcentrated flows or debris flows covering their banks.

Altogether, these water sources were likely to small to host an extensive standing body of water in Hellas. Whereas we found morphological evidence for an extensive sedimentary bank (consisting of lighttoned deposits) along the northern and northeastern inner rim of Hellas, we could not identify clear evidence for ancient shorelines. However, the floor of Hellas Planitia contains several small depressions with landforms such as possible arcuate shorelines, light-toned deposits, or 
tombolos that could have been formed by lacustrine processes.

In summary, our mapping results indicate that the high air pressure and wind circulation patterns in Hellas Planitia may have caused spatially inhomogeneous sublimation, and hence, desiccation of the surface. This might be a reason for a lack of several landforms like VFFs or gullies that are widespread at the same latitudes in other parts of Martian surface. Fluvial landforms of different ages suggest that Hellas Planitia experienced surface runoff (although in different quantities and rates) over much of the Martian history. However, no clear evidence has been found that would indicate an extensive sea in the basin. Instead, we suggest that Hellas may have contained at least several smaller lakes.

Grid mapping improved our understanding of Hellas Planitia and was able to discover characteristics of several landforms that can only be recognizable by a synoptic view. This method is also useful for geoscientific research on other celestial bodies for identifying large-scale coherences or connections between landforms.

\section{Acknowledgements}

We would like to acknowledge the helpful discussions with A. Johnsson (University of Gothenburg), as well as D. Tirsch and B. Heldt (both German Aerospace Center). Moreover, this work would not have been possible without the efforts of the CTX, MOLA, and HRSC team producing and archiving their excellent datasets. This work has been supported by the HRSC project and the COST-STSM (TD1308-090116070470) program funded by the E.U. Thoughtful comments from an anonymous reviewer helped to improve the manuscript and are highly appreciated.

\section{Appendix A. Supplementary data}

Supplementary data related to this article can be found at http://dx. doi.org/10.1016/j.pss.2017.07.012.

\section{References}

Ansan, V., Loizeau, D., Mangold, N., Le Mouélic, S., Carter, J., Poulet, F., Dromart, G., Lucas, A., Bibring, J.-P., Gendrin, A., Gondet, B., Langevin, Y., Masson, Ph, Murchie, S., Mustard, J.F., Neukum, G., 2011. Stratigraphy, mineralogy, and origin of layered deposits inside Terby crater, Mars. Icarus 211, 273-304. http://dx.doi.org/ 10.1016/j.icarus.2010.09.011.

Arkani-Hamed, J., 2005. Giant impact basins trace the ancient equator of Mars. J. Geophys. Res. 110 http://dx.doi.org/10.1029/2004JE002343. E04012.

Arkani-Hamed, J., 2010. Hellas: a Double-impact Basin. American Geophysical Union. Fall Meeting 2010, Abstract \#P51A-1409.

Bahrenberg, G., Giese, E., Nipper, J., 1999. Statistische Methoden in der Geographie. Band 1: Univariate und bivariate Statistik, p. 234.

Bandfield, J.L., Amador, E.S., Thomas, N.H., 2015. Extensive hydrated silica materials in western Hellas Basin, Mars. Icarus 226 (2013), 1489-1498. http://dx.doi.org/ 10.1016/j.icarus.2013.08.005.

Bernhardt, H., Hiesinger, H., Ivanov, M.A., Ruesch, O., Erkeling, G., Reiss, D., 2016a. Photogeologic mapping and the geologic history of the Hellas basin floor, Mars. Icarus 264 (2016), 407-442. http://dx.doi.org/10.1016/j.icarus.2015.09.031.

Bernhardt, H., Reiss, D., Hiesinger, H., Ivanov, M.A., 2016b. The honeycomb terrain on the Hellas basin floor, Mars: a case for salt or ice diapirism. J. Geophys. Res. Planets 121. http://dx.doi.org/10.1002/2016JE005007.

Brooker, L., Balme, M.R., Conway, S.J., Hagermann, A., Collins, G.S., 2015. EPSC Abstracts. Preliminary Grid Mapping of Fluvial, Glacial and Periglacial Landforms in and Around Lyot Crater, vol. 10. EPSC2015-P2810.

Cantor, B.A., 2007. . MOC observations of the 2001 Mars planet-encircling dust storm. Icarus 186 (2007), 60-96. http://dx.doi.org/10.1016/j.icarus.2006.08.019.

Cantor, B.A., James, P.B., Caplinger, M., Wolff, M.J., 2001. Martian Dust Storms: 1999 MOC Observations. J. Geophys. Res. 106 (E10), 23653-23687. http://dx.doi.org/ 10.1029/2000JE001310.

Carr, M.H., 2006. The Surface of Mars, p. 322.

Carter, J., Poulet, F., Bibring, J.-P., Mangold, N., Murchie, S., 2013. Hydrous minerals on Mars as seen by the CRISM and OMEGA imaging spectrometers: updated global view. J. Geophys. Res. 118, 831-858. http://dx.doi.org/10.1029/2012JE004145.

Carter, J., Loizeau, D., Quantin, C., Balme, M., Poulet, F., Gupta, S., Vago, J.L., Bibring, J.P., 2015. Mineralogic context of the circum-chryse planitia candidate landing sites for the exomars rover mission. In: 46th LPSC, \#1988.

Cedillo-Flores, Y., Treiman, A.H., Lasue, J., Clifford, S.M., 2011. CO2 gas fluidization in the initiation and formation of martian polar gullies. Geophys. Res. Lett. 38, L21202, http://dx.doi.org/10.1029/2011GL049403.
Christensen, P.R., 2003. Formation of recent martian gullies through melting of extensive water-rich snow deposits. Nature 422 (6927), 45-48. http://dx.doi.org/10.1038/ nature 01436.

Christensen, P.R., Jakosky, B.M., Kieffer, H.H., Malin, M.C., McSween Jr., H.Y., Nealson, K., Mehall, G.L., Silverman, S.H., Ferry, S., Caplinger, M., Ravine, M., 2004. The thermal emission imaging system (THEMIS) for the Mars 2001 Odyssey mission. Space Sci. Rev. 110, 85-130.

Chuang, F.C., Noe Dobrea, E.Z., Mest, S.C., Crown, D.A., 2015. Geomorphologic mapping and mineralogy of pits in intercrater plains, northwest circum Hellas region, Mars. In: 46th LPSC, \#2542.

Conway, S.J., Balme, M.R., 2014. Decameter thick remnant glacial ice deposits on Mars. Geophys. Res. Lett. 41 http://dx.doi.org/10.1002/2014GL060314.

Costa, J.E., 1988. Rheologic, geomorphic, and sedimentologic differentiation of water floods, hyperconcentrated flows, and debris flows. In: Baker, V.R., Kochel, R.C., Patton, P.C. (Eds.), Flood Geomorphology. John Wiley \& Sons, New York, pp. 113-122.

Costard, F.M., Kargel, J.S., 1995. Outwash plains and thermokarst on Mars. Icarus 114, 93-112. http://dx.doi.org/10.1006/icar.1995.1046.

Crown, D.A., Greeley, R., 2007. Geologic Map of MTM -30262 and -30267 Quadrangles, Hadriaca Patera Region of Mars, Scientific Investigations Map 2936, Atlas of Mars: MTM -30262 and -30267 Quadrangles.

Crown, D.A., Bleamaster, L.F., Mest, S.C., 2005. Styles and timing of volatile-driven activity in the eastern Hellas region of Mars. J. Geophys. Res. 110 (E12) http:// dx.doi.org/10.1029/2005JE002496. E12S22.

Dickson, J.L., Head, J.W., Goudge, T.A., Barbieri, L., 2015. Recent climate cycles on Mars: stratigraphic relationships between multiple generations of gullies and the latitude dependent mantle. Icarus 252, 83-94. http://dx.doi.org/10.1016/ j.icarus.2014.12.035.

Diniega, S., Hansen, C.J., McElwaine, J.N., Hugenholtz, C.H., Dundas, C.M., McEwen, A.S., Bourke, M.C., 2013. A new dry hypothesis for the formation of martian linear gullies. Icarus 225, 526-537. http://dx.doi.org/10.1016/ j.icarus.2013.04.006.

Diot, X., El-Maarry, M.R., Schlunegger, F., Norton, K.P., Thomas, N., Grindrod, P.M., 2014. The geomorphology and morphometry of the banded terrain in Hellas basin, Mars. Planet. Space Sci. 101, 118-134. http://dx.doi.org/10.1016/ j.pss.2014.06.013.

Diot, X., El-Maarry, M.R., Schlunegger, F., Norton, K.P., Thomas, N., Grindrod, P.M., Chojnacki, M., 2016. Complex geomorphologic assemblage of terrains in association with the banded terrain in Hellas basin, Mars. Planet. Space Sci. 121, 36-52. http:// dx.doi.org/10.1016/j.pss.2015.12.003.

Dundas, C.M., Byrne, S., McEwen, A.S., 2015a. Modeling the development of martian sublimation thermokarst landforms. Icarus 262, 154-169. http://dx.doi.org/ 10.1016/j.icarus.2015.07.033.

Dundas, C.M., Dieniega, S., McEwen, A.S., 2015b. Long-term monitoring of martian gully formation and evolution with MRO/HiRISE. Icarus 251, 244-263. http://dx.doi.org/ 10.1016/j.icarus.2014.05.013.

Feldman, W.C., Prettyman, T.H., Maurice, S., Plaut, J.J., Bish, D.L., Vaniman, D.T. Mellon, M.T., Metzger, A.E., Squyres, S.W., Karunatillake, S., Boynton, W.V., Elphic, R.C., Funsten, H.O., Lawrence, D.J., Tokar, R.L., 2004. Global distribution of near-surface hydrogen on Mars. J. Geophys. Res. 109 http://dx.doi.org/10.1029/ 2003JE002160. E09006.

Fergason, R.L., Christensen, P.R., Kieffer, H.H., 2006. High-resolution thermal inertia derived from the thermal emission imaging system (THEMIS): thermal model and applications. J. Geophys. Res. 111 http://dx.doi.org/10.1029/2006JE002735. E12004.

Forget, F., Hourdin, F., Fournier, R., Hourdin, C., Talagrand, O., Collins, M., Lewis, S.R., Read, P.L., Huot, J.-P., 1999. Improved general circulation models of the Martian atmosphere from the surface to above $80 \mathrm{~km}$. J. Geophys. Res. 104 (E10) 24155-24176. http://dx.doi.org/10.1029/1999JE001025.

Forget, F., Haberle, R., Montmessin, F., Levrard, B., Head, J.W., 2006. Formation of glaciers on Mars by atmospheric precipitation at high obliquity. Science 311 , 368-371. http://dx.doi.org/10.1126/science.1120335.

Greeley, R., Leach, R., White, B., Iverson, J., Pollacl, J.B., 1980. Threshold wind speeds for sand on Mars: wind tunnel simulations. Geophys. Res. Lett. 7 (2), 121-124.

Haberle, R.M., McKay, C.P., Schaeffer, J., Cabrol, N.A., Grin, E.A., Zent, A.P., Quinn, R., 2001. On the possibility of liquid water on present-day Mars. J. Geophys. Res. 106 (E10), 23317-23326. http://dx.doi.org/10.1029/2000JE001360.

Haberle, R.M., Murphy, J.R., Schaeffer, J., 2003. Orbital change experiments with a Mars general circulation model. Icarus 161, 66-89. http://dx.doi.org/10.1016/S00191035(02)00017-9.

Hansen, C.J., Thomas, N., Portyankina, A., McEwen, T., Becker, S., Herkenhoff, K., Kieffer, H., Mellon, M., 2010. HiRISE observations of gas sublimation-driven activity in Mars' southern polar regions: I. Erosion of the surface. Icarus 205, 283-295. http:// dx.doi.org/10.1016/j.icarus.2009.07.021.

Hargitai, H.I., Gulick, V.C., Glines, N.H., 2017. Discontinuous drainage systems formed by highland precipitation and ground-water outflow in the Navua Valles and southwest Hadriacus Mons regions, Mars. Icarus 294, 172-200. http://dx.doi.org/10.1016/ j.icarus.2017.03.005.

Harrison, T.N., Osinski, G.R., Tornabene, L.L., Jones, E., 2015. Global documentation of gullies with the Mars Reconnaissance orbiter context camera and implications for their formation. Icarus 252, 236-254. http://dx.doi.org/10.1016/ j.icarus.2015.01.022.

Hauber, E., Orgel, C., van Gasselt, S., Reiss, D., Johnsson, A., Ramsdale, J.D., Balme, M.R., Conway, S.J., Costard, F., Gallagher, C., Kereszturi, Á., Platz, T., Séjourné, A., Skinner, J.A., Swirad, Z., Losiak, A., 2015. Mapping Mars' northern plains: origins, 
evolution and response to climate change - a new overview of recent ice-related landforms in Acidalia Planitia. In: 46th LPSC, \#1359.

Hayward, R.K., Fenton, L.K., Titus, T.N., 2014. Mars global digital dune Database (MGD ${ }^{3}$ ): global dune distribution and wind pattern observations. Icarus 230, 38-46. http:// dx.doi.org/10.1016/j.icarus.2013.04.011.

Head, J.W., Mustard, J.F., Kreslavsky, M.A., Milliken, R.E., Marchant, D.R., 2003. Recent ice ages on Mars. Nature 426, 797-802. http://dx.doi.org/10.1038/nature02114.

Howard, A.D., 2000. The role of eolian processes in forming surface features of the martian polar layered deposits. Icarus 144, 267-288. http://dx.doi.org/10.1006/ icar.1999.6305.

Howard, A.D., Spiga, A., Moore, J.M., 2012. The deepest basin on Mars is formed by aeolian erosion: western Hellas planitia. In: 43rd LPSC, \#1105.

Hubbard, B., Souness, C., Brough, S., 2014. glacier-like forms on Mars. Cryosphere 8, 2047-2061. http://dx.doi.org/10.5194/tc-8-2047-2014.

Jenness, J., 2012. Repeating Shapes for ArcGIS. Jenness Enterprises. Available at. http:// www.jennessent.com/arcgis/repeat shapes.htm.

Kahre, M.A., Hollingsworth, J.L., Haberle, R.M., Wolff, M.J., 2014. Understanding the formation and evolution of water ice clouds in the Hellas basin during NH summer on Mars. In: 8th International Conference on Mars, \#1308.

Keszthelyi, L., Thordarson, T., McEwen, A., Haack, H., Guilbaud, M.-N., Self, S., Rossi, M.J., 2004. Icelandic analogs to Martian flood lavas. Geochem. Geophys. Geosyst. 5, Q11014,. http://dx.doi.org/10.1029/2004GC000758.

Kieffer, H.H., Jakosky, B.M., Snyder, C.W., 1992. In: Kieffer, H.H., et al. (Eds.), The Planet Mars: from Antiquity to the Present in Mars. University Arizona Press, Tucson, London.

Kostama, V.-P., Kreslavsky, M.A., Head, J.W., 2006. Recent high-latitude icy mantle in the northern plains of Mars: characteristics and ages of emplacement. Geophys. Res. Lett. 33, L11201,. http://dx.doi.org/10.1029/2006GL025946.

Kostama, V.-P., Ivanov, M.A., Raitala, J., Törmänen, T., Korteniemi, J., Neukum, G., 2010 Evidence for multiple ice deposits on the northeastern rim of Hellas basin, Mars. Earth Planet. Sci. Lett. 294, 321-331. http://dx.doi.org/10.1016/j.epsl.2009.11.021.

Kreslavsky, M.A., Head, J.W., 2002. Mars: nature and evolution of young latitudedependent water-ice-rich mantle. Geophys. Res. Lett. 29 (15), 1719,. http:// dx.doi.org/10.1029/2002GL015392.

Laskar, J., Correia, A.C.M., Gastineau, M., Joutel, F., Levrard, B., Robutel, P., 2004. Long term evolution and chaotic diffusion of the insolation quantities of Mars. Icarus 170 343-364. http://dx.doi.org/10.1016/j.icarus.2004.04.005.

Lefort, A., Russell, P.S., Thomas, N., McEwen, A.S., Dundas, C.M., Kirk, R.L., 2009. Observations of periglacial landforms in Utopia Planitia with the high resolution imaging science experiment (HiRISE). J. Geophys. Res. 114 http://dx.doi.org/ 10.1029/2008JE003264. E04005.

Leonard, G.J., Tanaka, K.L., 2001. Geologic map of the Hellas region of Mars. U. S. Geol. Surv. Misc. Invest. Ser. Map I-2694.

Leverington, D.W., 2011. Volcanic origin for the outflow channels of Mars: key evidence and major implications. Geomorphology 132, 51-75. http://dx.doi.org/10.1016/ j.geomorph.2011.05.022.

Levrard, B., Forget, F., Montmessin, F., Laskar, J., 2004. Recent ice-rich deposits formed at high latitudes on Mars by sublimation of unstable equatorial ice during low obliquity. Nature 431, 1072-1075. http://dx.doi.org/10.1038/nature03055.

Madeleine, J.B., Head, J.W., Forget, F., Navarro, T., Millour, E., 2014. Recent ice ages on Mars: the role of Radiatively active clouds and cloud microphysics,. Geophys. Res. Lett. 41, 4873-4879. http://dx.doi.org/10.1002/2014GL059861.

Malin, M.C., Bell III, J.F., Cantor, B.A., Caplinger, M.A., Calvin, W.M., Clancy, R.T., Edgett, K.S., Edwards, L., Haberle, R.M., James, P.B., Lee, S.W., Ravine, M.A., Thomas, P.C., Wolff, M.J., 2007. Context camera investigation on board the Mars Reconnaissance orbiter. J. Geophys. Res. 112 http://dx.doi.org/10.1029/ 2006JE002808. E05S04.

Malin, M.C., Edgett, K.S., 2000. Evidence for recent Groundwater Seepage and Surface Runoff on Mars. Science 288, 2330-2335. http://dx.doi.org/10.1126/ science.288.5475.2330.

Mangold, N., 2011. Ice sublimation as a geomorphic process: a planetary perspective, Geomorphology 126, 1-17. http://dx.doi.org/10.1016/j.geomorph.2010.11.009.

Mangold, N., Allemand, P., 2003. Ductile deformation in Hellas floor: salt diapirs or crustal domes?. In: 6th International Conference on Mars, \#3047.

Mest, S.C., Crown, D.A., 2001. Geology of the Reull Vallis region, Mars. Icarus 153, 89-110. http://dx.doi.org/10.1006/icar.2001.6655.

Milliken, R.E., Mustard, J.F., Goldsby, D.L., 2003. Viscous flow features on the surface of Mars: observations from high-resolution Mars Orbiter Camera (MOC) images. J. Geophys. Res. 108 (E6), 5057,. http://dx.doi.org/10.1029/2002JE002005.

Millour, E., Forget, F., Spiga, A., Navarro, T., Madeleine, J.-B., Montabone, L., Pottier, A., Lefevre, F., Montmessin, F., Chaufray, J.-Y., Lopez-Valverde, M.A., GonzalezGalindo, F., Lewis, S.R., Read, P.L., Huot, J.-P., Desjean, M.-C. the MCD/GCM development team, 2015. The Mars Climate Database (MCD Version 5.2). EPSC Abstracts, vol. 10. EPSC2015-P2438.

Mischna, M.A., Richardson, M.I., Wilson, R.J., McCleese, D.J., 2003. On the orbital forcing of Martian water and $\mathrm{CO} 2$ cycles: a general circulation model study with simplified volatile schemes. J. Geophys. Res. 108 (E6), 5062,. http://dx.doi.org/ 10.1029/2003JE002051.

Moore, J.M., Wilhelms, D.E., 2001. Hellas as a possible site of ancient ice-covered lakes on Mars. Icarus 154, 258-276. http://dx.doi.org/10.1006/icar.2001.6736.

Moore, J.M., Wilhelms, D.E., 2007. Geologic Map of Part of Western Hellas Planitia, Mars. U.S. Geological Survey Geologic Investigations, p. 80225, 2953.

Morgenstern, A., Hauber, E., Reiss, D., van Gasselt, S., Grosse, G., Schirrmeister, L., 2007. Deposition and degradation of a volatile-rich layer in Utopia Planitia and implication for climate history on Mars. J. Geophys. Res. 112 http://dx.doi.org/10.1029/ 2006JE002869. E06010.
Mustard, J.F., Cooper, C.D., Rifkin, M.K., 2001. Evidence for recent climate change on Mars from the identification of youthful near-surface ground ice. Nature 412 , 411-414. http://dx.doi.org/10.1038/35086515.

Neumann, G.A., Zuber, M.T., Wieczorek, M.A., McGovern, P.J., Lemoine, F.G., Smith, D.E., 2004. Crustal structure of Mars from gravity and topography. J. Geophys. Res. 109 http://dx.doi.org/10.1029/2004JE002262. E08002.

Ogohara, K., Satomura, T., 2008. Northward movement of Martian dust localized in the region of the Hellas Basin. Geophys. Res. Lett. 35 http://dx.doi.org/10.1029/ 2008GL034546. L13201.

Orgel, C., Hauber, E., Skinner, J.A., van Gasselt, S., Ramsdale, J.D., Balme, M.R., Séjourné, Kereszturi, Á., 2015. Distribution, origin and evolution of hypothesized mud volcanoes, thumbprint terrain and giant polygons in Acidalia, Utopia and Arcadia Planitiae: implications for sedimentary processes in the northern lowlands of Mars. In: 46th LPSC, \#1862.

Panizza, M., 1996. Environmental Geomorphology - Developments in Earth Surface Processes, vol. 4, p. 267.

Ramsdale, J., Balme, M., Conway, S., Gallagher, C., van Gasselt, S., Hauber, E., Orgel, C., Séjourné, A., Skinner, J., Costard, F., Johnsson, A., Losiak, A., Reiss, D., Swirad, Z., Kereszturi, A., Smith, I., Platz, T., 2017. Grid-based mapping: a method for rapidly determining the spatial distributions of small features over very large areas. Planet. Space Sci. 140, 49-61. http://dx.doi.org/10.1016/j.pss.2017.04.002.

Richardson, M.I., Wilson, R.J., 2002. Investigation of the nature and stability of the Martian seasonal water cycle with a general circulation model. J. Geophys. Res. 107 (E5), 5031,. http://dx.doi.org/10.1029/2001JE001536.

Ruff, S.W., Christensen, P.R., 2002. Bright and dark regions on Mars: particle size and mineralogical characteristics based on thermal emission spectrometer data. J. Geophys. Res. 107 http://dx.doi.org/10.1029/2001JE001580.

Salese, F., Ansan, V., Mangold, N., Carter, J., Ody, A., Poulet, F., Ori, G.G., 2016. A sedimentary origin for intercrater plains north of the Hellas basin: implications for climate conditions and erosion rates on early Mars. J. Geophys. Res. Planets 121. http://dx.doi.org/10.1002/2016JE005039.

Schon, S.C., Head, J.W., Milliken, R.E., 2009. A recent ice age on Mars: evidence for climate oscillations from regional layering in mid-latitude mantling deposits, Geophys. Res. Lett. 36, L15202,. http://dx.doi.org/10.1029/2009GL038554.

Schon, S.C., Head, J.W., Fassett, C.I., 2012. Recent high-latitude resurfacing by a climaterelated latitude-dependent mantle: constraining age of emplacement from counts of small craters. Planet. Space Sci. 69, 49-61. http://dx.doi.org/10.1016/ j.pss.2012.03.015.

Schuster, D.L., Weiss, B.P., 2005. Martian Surface Paleotemperatures from Thermochronology of Meteorites. Science 309, 594-597. http://dx.doi.org/10.1126/ science. 1113077.

Séjourné, A., Costard, F., Gargani, J., Soare, R.J., Fedorov, A., Marmo, C., 2011. Scalloped depressions and small-sized polygons in western Utopia Planitia, Mars: a new formation hypothesis. Planet. Space Sci. 59 (5-6), 412-422. http://dx.doi.org/ 10.1016/j.pss.2011.01.007.

Séjourné, A., Costard, F., Losiak, A., Swirad, Z.M., Balme, M.R., Conway, S.J., Gallagher, C., Hauber, E., Johnsson, A.E., Kereszturi, A., Orgel, C., Platz, T., Ramsdale, J.D., Reiss, D., Skinner Jr., J.A., van Gasselt, S., 2015. Mapping the northern plains of Mars: origins, evolution and response to climate change - a new overview of recent ice-related landforms in utopia planitia. In: 46th LPSC, \#1328.

Shinbrot, T., Duong, N.-H., Kwan, L., Alvarez, M.M., 2003. Dry granular flows can generate surface features resembling those seen in Martian gullies. Proc. Natl. Acad. Sci. 101 (23), 8542-8546. http://dx.doi.org/10.1073/pnas.0308251101.

Siili, T., Haberle, R.M., Murphy, J.R., Savijärvi, H., 1999. Modelling of the combined latewinter ice cap edge and slope winds in Mars Hellas and Argyre regions. Planet. Space Sci. 47, 951-970. http://dx.doi.org/10.1016/S0032-0633(99)00016-1.

Smith, D.E., Zuber, M.T., Solomon, S.C., Phillips, R.J., Head, J.W., Garvin, J.B., Banerdt, W.B., Muhleman, D.O., Pettengill, G.H., Neumann, G.A., Lemoine, F.G. Abshire, J.B., Aharonson, O., Brown, C.D., Hauck, S.A., Ivanov, A.B., McGovern, P.J., Zwally, H.J., Duxbury, T.C., 1999. The global topography of Mars and implications for surface evolution. Science 284, 1421-1576. http://dx.doi.org/10.1126/ science.284.5419.1495.

Smith, D.E., Zuber, M.T., Frey, H.V., Garvin, J.B., Head, J.W., Muhleman, D.O., Pettengill, G.H., Phillips, R.J., Solomon, S.C., Zwally, H.J., Banerdt, W.B., Duxbury, T.C., Golombek, M.P., Lemoine, F.G., Neumann, G.A., Rowlands, D.D., Aharonson, O., Ford, P.G., Ivanov, A.B., Johnson, C.L., McGovern, P.J., Abshire, J.B., Afzal, R.S., Sun, X., 2001. Mars orbiter laser altimeter: experiment summary after the first year of global mapping of Mars. J. Geophys. Res. 106, 23689-23722. http:// dx.doi.org/10.1029/2000JE001364.

Soare, R.J., Kargel, J.S., Osinski, G.R., Costard, F., 2007. Thermokarst processes and the origin of crater-rim gullies in Utopia and western Elysium Planitia. Icarus 191, 95-112. http://dx.doi.org/10.1016/j.epsl.2008.05.010.

Soare, R.J., Osinski, G.R., Roehm, C.L., 2008. Thermokarst lakes and ponds on Mars in the very recent (late Amazonian) past. Earth Planet. Sci. Lett. 272, 382-393. http:// dx.doi.org/10.1016/j.epsl.2008.05.010.

Soare, R.J., Séjourné, A., Pearce, G., Costard, F., Osinski, G.R., 2011. The Tuktoyaktuk Coastlands of northern Canada: a possible "wet" periglacial analog of Utopia Planitia, Mars. Geol. Soc. Amer. Spec. Pap. 483, 203-218. http://dx.doi.org/10.1130/ 2011.2483(13).

Sturges, H.A., 1926. The choice of class interval. J. Am. Stat. Assoc. 21, 65-66.

Tanaka, K.L., Leonard, G.J., 1995. Geology and landscape evolution of the Hellas region of Mars. J. Geophys. Res. 100, 5407-5432. http://dx.doi.org/10.1029/94JE02804.

Tirsch, D., Jaumann, R., Pacifici, A., Poulet, F., 2011. Dark aeolian sediments in martian craters: composition and sources. J. Geophys. Res. 116 http://dx.doi.org/10.1029/ 2009JE003562. E03002. 
Treiman, A.H., 2003. Geologic settings of martian gullies: implications for their origins. J. Geophys. Res. 108 (E4) http://dx.doi.org/10.1029/2002JE001900, 8031.

Ulrich, M., Morgenstern, A., Günther, F., Bauch, K.E., Hauber, E., Rössler, S., Schirrmeister, L., 2010. Thermokarst in Siberian ice-rich permafrost: comparison to asymmetric scalloped depressions on Mars. J. Geophys. Res. 115, E10009,. http:// dx.doi.org/10.1029/2010JE003640.

Van Gasselt, S., 2007. Cold-climate landforms on Mars. Berichte aus der Geowissenschaft, D 188. Freie Universität Berlin.

Van Gasselt, S., Hauber, E., Neukum, G., 2007a. Cold-climate modification of Martian landscapes: a case study of a spatulate debris landform in the Hellas Montes region, Mars. J. Geophys. Res. 112 http://dx.doi.org/10.1029/2006JE002842. E09006.

Van Gasselt, S., Hauber, E., Neukum, G., 2010. Lineated valley fill at the Martian dichotomy boundary: nature and history of degradation. J. Geophys. Res. 115 http:// dx.doi.org/10.1029/2009JE003336. E08003.

Voelker, M., Platz, T., Tanaka, K.L., Fortezzo, C.M., Fergason, R., Hare, T.M., 2013. Hyperconcentrated flow deposits and valley formation of havel Vallis, Xanthe Terra, Mars. In: 44th LPSC, \#2886.

Voelker, M., Hauber, E., Jaumann, R., 2017. Extensive sheet deposits in eastern Hellas planitia - volcanic flows or cryofluvial deposits - a comparison. In: $48^{\text {th }}$ LPSC, \#1426.

Weischet, W., 2002. Einführung in die Allgemeine Klimatologie - Physikalische und meteorologische Grundlagen, sixth ed. Gebrüder Bornträger, Berlin, Stuttgart, p. 276.

Weiss, D.K., Head, J.W., 2017. Salt or ice diapirism origin for the honeycomb terrain in Hellas basin, Mars?: Implications for the early martian climate. Icarus 284, 249-263. http://dx.doi.org/10.1016/j.icarus.2016.11.016.
Werner, S.C., 2008. The early martian evolution--Constraints from basin formation ages. Icarus 195 (1), 45-60. http://dx.doi.org/10.1016/j.icarus.2007.12.008.

Williams, D.A., Greeley, R., Fergason, R.L., Kuzmin, R., McCord, T.B., Combe, J.-P., Head, J.W., Xiao, L., Manfredi, L., Poulet, F., Pinet, P., Baratoux, D., Plaut, J.J., Raitala, J., Neukum, G., the HRSC Co-Investigator Team, 2010. The circum-hellas volcanic province, Mars: overview. Planet. Space Sci. 57, 895-916. http:// dx.doi.org/10.1016/j.pss.2008.08.010.

Willmes, M., Reiss, D., Hiesinger, H., Zanetti, M., 2012. Surface age of the ice-dust mantle deposit in Malea Planum, Mars. Planet. Space Sci. 60, 199-206. http://dx.doi.org/ 10.1016/j.pss.2011.08.006.

Wilson, S., Howard, A.D., Moore, J.M., Grant, J.A., 2007. Geomorphic and stratigraphic analysis of Crater Terby and layered deposits north of Hellas basin, Mars. J. Geophys. Res. 112 http://dx.doi.org/10.1029/2006JE002830. E08009.

Zanetti, M., Hiesinger, H., Reiss, D., Hauber, E., Neukum, G., 2010. Distribution and evolution of scalloped terrain in the southern hemisphere, Mars. Icarus 206 , 691-706. http://dx.doi.org/10.1016/j.icarus.2009.09.010.

Zimbelman, J.R., Garry, W.B., Bleacher, J.E., Crumpler, L.S., 2011. Inflation features on the Distal Pahoehoe portion of the 1859 Mauna Loa Flow, Hawaii: implications for evaluating planetary lava flows. In: 42nd LPSC, \#2443.

Zuschneid, van Gasselt, 2014. Evidence for volcanism on the western Hellas basin floor. In: 46th LPSC, \#1858. 